
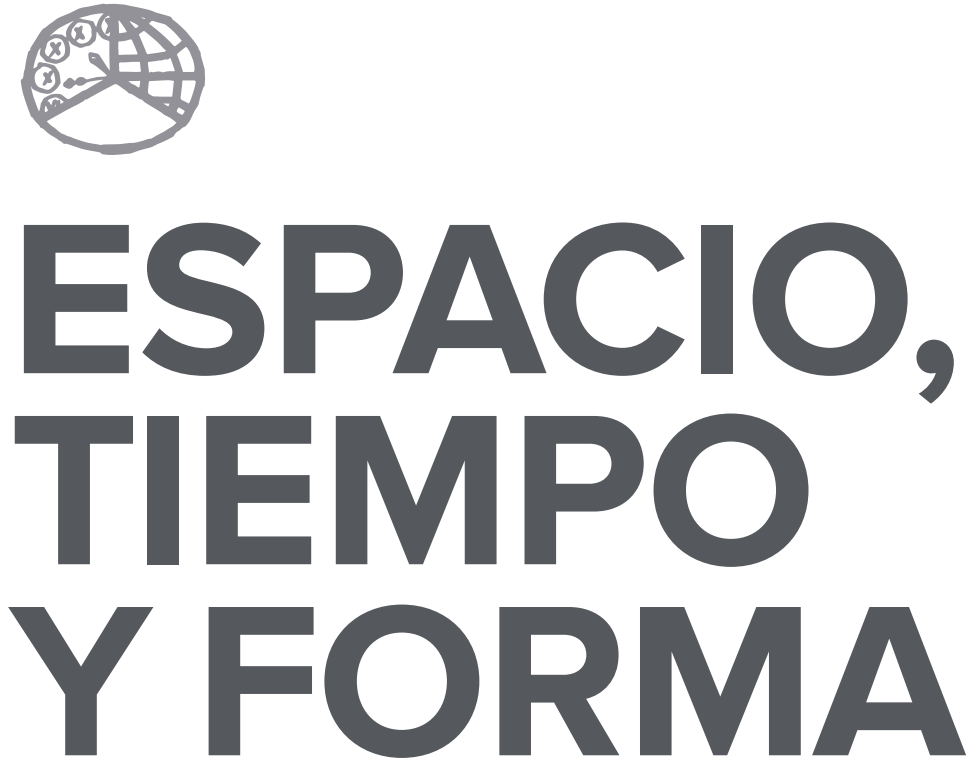

AÑO 2021

ISSN 0214-9745

E-ISSN 2340-1362

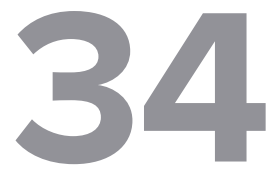

SERIE III HISTORIA MEDIEVAL

REVISTA DE LA FACULTAD DE GEOGRAFÍA E HISTORIA

VOLUMEN I 


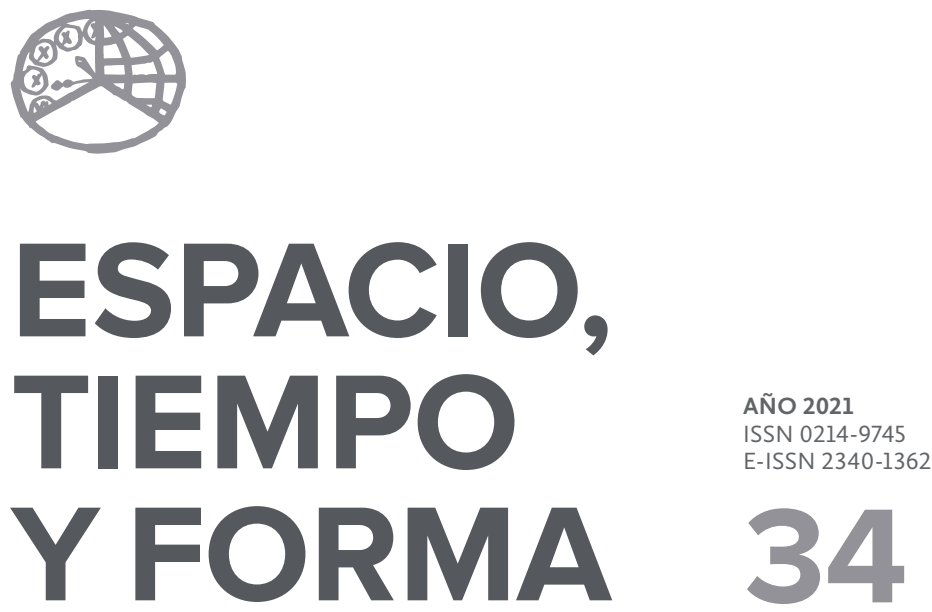

SERIE III HISTORIA MEDIEVAL

REVISTA DE LA FACULTAD DE GEOGRAFÍA E HISTORIA

VOLUMEN I

http://dx.doi.org/10.5944/etfiii.34.2021

\section{UกED}

UNIVERSIDAD NACIONAL DE EDUCACIÓN A DISTANCIA 
La revista Espacio, Tiempo y Forma (siglas recomendadas: ETF),

de la Facultad de Geografía e Historia de la UNED, que inició su publicación el año 1988, está organizada de la siguiente forma:

$$
\begin{aligned}
& \text { SERIE I - Prehistoria y Arqueología } \\
& \text { SERIE II - Historia Antigua } \\
& \text { SERIE III - Historia Medieval } \\
& \text { SERIE IV - Historia Moderna } \\
& \text { SERIE V - Historia Contemporánea } \\
& \text { SERIE VI - Geografía } \\
& \text { SERIE VII - Historia del Arte }
\end{aligned}
$$

Excepcionalmente, algunos volúmenes del año 1988 atienden a la siguiente numeración:
N. ${ }^{\circ} 1 \quad-$ Historia Contemporánea
N. ${ }^{\circ} 2-$ Historia del Arte
N. ${ }^{\circ} 3-$ Geografía
N. ${ }^{\circ} 4 \quad-$ Historia Moderna

ETF no se solidariza necesariamente con las opiniones expresadas por los autores.

UNIVERSIDAD NACIONAL DE EDUCACIÓN A DISTANCIA

Madrid, 2021

SERIE III - HISTORIA MEDIEVAL N. ${ }^{\circ} 34,2021$

ISSN 0214-9745 · E-ISSN 2340-1362

DEPÓSITO LEGAL M-21037-1988

URL: ETF III · HISTORIA MEDIEVAL · http://revistas.uned.es/index.php/ETFIII

DISEÑO Y COMPOSICIÓN

Carmen Chincoa Gallardo · http://www.laurisilva.net/cch

Impreso en España $\cdot$ Printed in Spain 
Espacio, Tiempo y Forma. Serie III. Historia Medieval es la revista científica fundada en I988 que publica el Departamento de Historia Medieval y Ciencias y Técnicas Historiográficas de la Facultad de Geografía e Historia de la UNED. Está dedicada al estudio de la Historia Medieval y acoge trabajos inéditos de investigación, en especial artículos que constituyan una aportación novedosa, que enriquezcan el campo de estudio que abordan y que ofrezcan una perspectiva de análisis crítico. Va dirigida preferentemente a la comunidad científica y universitaria, tanto nacional como internacional, así como a todos los profesionales de la Historia Medieval en general. Su periodicidad es anual y se somete al sistema de revisión por pares ciegos. La revista facilita el acceso sin restricciones a todo su contenido desde el momento de su publicación en edición electrónica. Espacio, Tiempo y Forma. Serie III. Historia Medieval se publica en formato electrónico y en papel.
Espacio, Tiempo y Forma. Serie III. Historia Medieval (Space, Time and Form. Series III. Medieval History) is a peerreviewed academic journal founded in I988 and published by the Department of Medieval History and Historiographical Sciences and Techniques at the Faculty of Geography and History, UNED. It is devoted to the study of Medieval History and is addressed to the Spanish and international scholarly community, as well as to professionals in the field of Medieval History. The journal welcomes previously unpublished articles, particularly works that provide an innovative approach, contribute to its field of research and offer a critical analysis. It is published annually. The journal provides complete open access to its content available online upon publication. Espacio, Tiempo y Forma. Serie III. Historia Medieval is published online and in print and is indexed in the databases and directories enumerated below.

Espacio, Tiempo y Forma. Serie III. Historia Medieval está registrada e indexada en Repertorios Bibliográficos y Bases de Datos nacionales e internacionales, como recomiendan los criterios de la Comisión Nacional Evaluadora de la Actividad Investigadora: LATINDEX, DICE, ISOC (CINDOC), RESH, INRECH, Dialnet, e-spacio UNED, CIRC 2.o (20I6), MIAR, FRANCIS, PIO, Ulrich's, SUDOC, ZDB, ERIH (ESF), REDIB, Repertorio de Medievalismo Hispánico, Directory of Open Access Journals (DOAJ), Emerging Sources Citation Index (ESCI), SCOPUS. La revista ha obtenido el Sello de Calidad de la FECYT (2018).

\section{EQUIPO EDITORIAL}

Edita: Departamento de Historia Medieval y Ciencias y Técnicas Historiográficas, Universidad Nacional de Educación a Distancia

Director del Consejo de Redacción: Enrique Cantera Montenegro (UNED)

Editores: Enrique Cantera Montenegro (UNED), Carlos Barquero Goñi (UNED) 
CONSEJO DE REDACCIÓN

Cristina Álvarez Millán

Departamento de Historia Medieval y Ciencias y Técnicas Historiográficas, UNED

Ana Arranz Guzmán

Universidad Complutense de Madrid

Carlos de Ayala Martínez

Universidad Autónoma de Madrid

Carlos Barquero Goñi

Departamento de Historia Medieval y Ciencias y Técnicas Historiográficas, UNED

Enrique Cantera Montenegro

Departamento de Historia Medieval y Ciencias y Técnicas Historiográficas, UNED

Ana Echevarría Arsuaga

Departamento de Historia Medieval y Ciencias y Técnicas Historiográficas, UNED

José María de Francisco Olmos

Universidad Complutense de Madrid

María Jesús Fuente Pérez

Universidad Carlos III de Madrid

Manuel Fernando Ladero Quesada

Departamento de Historia Medieval y Ciencias y Técnicas Historiográficas, UNED

Paulina López Pita

Departamento de Historia Medieval y Ciencias y Técnicas Historiográficas, UNED

José Miguel López Villalba

Departamento de Historia Medieval y Ciencias y Técnicas Historiográficas, UNED

José María Monsalvo Antón

Universidad de Salamanca

Isabel Montes Romero-Camacho

Universidad de Sevilla

Gonzalo Viñuales Ferreiro

Universidad Rey Juan Carlos

COMITÉ CIENTÍFICO

Vicente Ángel Álvarez Palenzuela

Universidad Autónoma de Madrid

Daniel Baloup

Université de Toulouse-Le Mirail

Vicente García Lobo

Universidad de León

María Estela González de Fauve

Universidad de Buenos Aires · Fundación para la Historia de España

César González Mínguez

Universidad del País Vasco 
Nikolas Jaspert

Ruhr-Universität Bochum, Alemania

DIRECTORA DE ETF SERIES I-VII

Yayo Aznar Almazán

Decana Facultad de Geografía e Historia, UNED

SECRETARIO DE ETF SERIES I-VII

Julio Fernández Portela

Departamento de Geografía, UNED

GESTORA PLATAFORMA OJS

Carmen Chincoa Gallardo

COMITÉ EDITORIAL DE ETF SERIES I-VII

Carlos Barquero Goñi, Departamento de Historia Medieval y Ciencias y Técnicas Historiográficas, UNED; Enrique Cantera Montenegro, Departamento de Historia Medieval y Ciencias y Técnicas Historiográficas, Uned; Pilar Díez del Corral Corredoira, Departamento de Historia del Arte, UneD; Carmen Guiral Pelegrín, Departamento de Prehistoria y Arqueología (Arqueología), Uned; Patricia Hevia Gómez, Departamento de Prehistoria y Arqueología (Arqueología), unED; Luiza lordache Cârstea, Departamento de Historia Contemporánea, UNED; M. ${ }^{a}$ Luisa de Lázaro Torres, Departamento de Geografía, Uned; David Martín Marcos, Departamento de Historia Moderna, Uned; José Antonio Martínez Torres, Departamento de Historia Moderna, UnED; Íñigo García Martínez de Lagrán, Departamento de Prehistoria y Arqueología (Prehistoria), UnED; Álvaro Molina Martín, Departamento de Historia del Arte, Uned; Francisco Javier Muñoz Ibáñez, Departamento de Prehistoria y Arqueología (Prehistoria), UNED; Rocío Negrete Peña, Departamento de Historia Contemporánea, UnED; Miguel Ángel Novillo López, Departamento de Historia Antigua, UnED.

CORRESPONDENCIA

Revista Espacio, Tiempo y Forma

Facultad de Geografía e Historia, UNED

c/ Senda del Rey, 7

28040 Madrid

e-mail: revista-etf@geo.uned.es 



\section{SUMARIO · SUMMARY}

\section{VOLUMEN I}

13 Artículos $\cdot$ Articles

15 Patricia A. Argüelles Álvarez

Peligros, inseguridades y problemas del viajero visigodo

Danger, Lack of Safety and Problems for the Visigothic Traveller

37 Carmen Barceló, Ana labarta, Josep Benedito \& José M. Melchor Cuatro cerámicas con epigrafía árabe del Museu de Borriana

Four Ceramic Pieces with Arabic Inscriptions in the Archeological Museum of Borriana

65 Carlos Barquero Goñ

Organización de la Orden de San Juan en Castilla durante los siglos XII y XIII The Organization of the Order of Saint John in Castile during the Twelfth and Thirteenth Centuries

113 Francisco de Paula Cañas Gálvez

Una infanta de Navarra en la corte de Castilla: escenarios políticos en torno a la configuración y evolución del Hostal y la casa de Blanca de Trastámara, Princesa de Asturias (I424-†I464)

A Princess of Navarre in the Court of Castile: Political Scenarios in the Configuration and Evolution of the Hostal and Royal Household of Blanca of Trastámara, Princess of Asturias (I424-†I464)

165 David Caramazana Malia

Las promociones artísticas de Alonso de Ejea, arzobispo y administrador perpetuo de la Archidiócesis de Sevilla y patriarca de Constantinopla (I403-I4I7)

The Artistic Patronage of Alonso de Ejea, Archbishop and Perpetual Administrator of the Archdiocese of Seville and Patriarch of Constantinople (I403-I4I7) 
203 Pedro Castillo Maldonado

Privilegios episcopales: la inviolabilidad de los obispos visigóticos y el delito de lesa majestad

Episcopal Privileges: The Inviolability of Visigothic Bishops and the Crime of Lèse-Majesté

227 Máximo Diago HERnANDO

Alonso de Fonseca, Obispo de Ávila, Cuenca y Osma, y el ascenso de un linaje de exiliados portugueses en la Castilla de los siglos XV y XVI Alonso de Fonseca, Bishop of Ávila, Cuenca and Osma, and the Promotion in Castile of an Exiled Noble Family from Portugal during the Fifteenth and Sixteenth Centuries

263 Antonio PIO DI Cosmo

Santa Brigida ed il Monte Gargano: un paesaggio dell'anima. La descrizione dell'ambiente come stratagemma d'ammaestramento morale Saint Brigid and Mount Gargano: A Landscape of the Soul. The Description of the Environment as a Device for Moral Instruction

Santa Brígida y el Monte Gargano: un paisaje del alma. La descripción del medio ambiente como estrategia de entrenamiento moral

293 FERRAN ESQUiLACHE

La 'fila' de agua valenciana y otras medidas de aforo. La verdadera naturaleza de un sistema de medición de caudales de origen andalusí

The Valencian Water 'Fila' and other Systems of Gauging Liquid Capacity. The Actual Nature of a Measurement System of Water Flow of Andalusí Origin

323 Alejandro Esteban Álvarez

Habices del Reino de Granada averiguados en I528 y I53I: la țā‘a nazarí de Órgiva (Alpujarra)

Habices of the Kingdom of Granada Ascertained in 1528 and I53I: The Nasrid tạa'a of Órgiva (Alpujarra)

359 Javier Gómez Gómez e Iñakı Martín Viso

Rationes y decimas: evidencias sobre la gestión de las sernas en el siglo Xl en el noroeste de la Península Ibérica

Rationes and Decimas: Some Evidences on the Management of Eleventh Century Sernas in Northwestern Iberia 
383 Santiago González Sánchez

Aportaciones de Paredes de Nava a las campañas militares del Infante Don Fernando, señor de la villa y regente de Castilla, contra el Reino Nazarí de Granada en I407 y en I4IO

The Contribution of Paredes de Nava to the Military Campaigns of the Infante Fernando, Lord of the Town and Regent of Castile, against the Nasrid Kingdom of Granada in 1407 and I4IO

429 ANTONI LLIBRER ESCRIG

Una máquina para la industria medieval. Los batanes del sur valenciano: integración y negocio. Nuevas aportaciones (I49O-I502)

A Machine for Medieval Industry. The Fulling Mills of the Valencian South: Integration and Business. New contributions (I49O-I502)

455 José Miguel López Villalba

Comunicación escrita y oral de la ordenanza municipal (siglos XV-XVI) Written and Oral Communication of Municipal Regulations (FifteenthSixteenth Centuries)

501 Emilio Martín Gutiérrez

El aprovechamiento de los recursos naturales: la grana en Andalucía occidental durante el siglo XV

The Use of Natural Resources: Grana Pigmentin Western Andalusia during the Fifteenth Century

\section{VOLUMEN II}

537 Vera-Cruz Miranda Menacho

Las finanzas de un heredero: Carlos de Aragón y Navarra (I42I-I46I)

A Crown Prince's Finances: Charles of Aragon and Navarre (I42I-I46I)

569 Raúl Morales Muñoz

Hacia una revalorización del conciliarismo hispano bajomedieval: el Defensorium Trium Conclusionum de Alfonso de Madrigal

Towards a Reappraisal of Late-Medieval Hispanic Conciliarism: Alfonso de Madrigal's Defensorium Trium Conclusionum 
605 David Nogales Rincón

Enrique III de Castilla (I390-I406) y la indagación de rentas: un proyecto regio para la búsqueda de mineros y tesoros a inicios del cuatrocientos Enrique III of Castile (I390-I406) and the Inquiry into Sources of Revenue: A Royal Project for the Quest of Mines And Treasures at the Turn of the Fifteenth Century

647 Gonzalo Oliva Manso

Seisenes y novenes. Tiempos de calma para la moneda castellano-leonesa (I282-I3I2)

The Seisén and the Novén. Times of Stability for the Castile-Leonese Currency (I282-I3I2)

685 Alberto Peña Fernández y Manuel García Alonso Una inscripción medieval inédita en la iglesia de San Miguel de Aguayo (Cantabria)

A Newly Found Medieval Inscription in the Church of San Miguel de Aguayo (Cantabria)

713 Rodrigo Pousa Diéguez

Configuración institucional de una villa costera: Muros en el tránsito de la Edad Media a la Edad Moderna

The Institutional Development of a Coastal Village: Muros between the Middle Ages and the Early Modern Times

745 Juan A. Prieto Sayagués

Las profesiones femeninas de la nobleza y de las oligarquías urbanas en la Castilla bajomedieval. Causas, dinámicas, privilegios y donaciones

Female Professions among the Nobility and the Urban Oligarchy in Late Medieval Castile. Causes, Dynamics, Privileges and Donations

815 María del Pilar Rábade Obradó

El miedo a la Inquisición en la Castilla de los Reyes Católicos

Fear of the Inquisition in Castile under the Catholic Monarchs

845 Carlos Manuel Reglero de la Fuente

EL abad contra el rey (y los regidores): conflicto de jurisdicciones y ejercicio del poder en Sahagún (I398-I4I7)

The Abbot versus The King (and the Town Councillors): Conflict between Jurisdictions and the Use of Power in Sahagún (I398-I4I7) 
881 Manuel Alejandro Rodríguez de la Peña

Eusebius and Alcuin on Constantine and Charlemagne as Wise Rulers:

Sapiential Rulership in Late Antiquity and the Early Middle Ages

Constantino y Carlomagno como gobernantes sabios en la obra de Eusebio de Cesarea y Alcuino de York: la realeza sapiencial en la Antigüedad Tardía y la Alta Edad Media

915 Antonio SÁnchez González

El Archivo de los Mariscales de Castilla y Marqueses de Malagón

The Archives of the Marshals of Castile and the Marquises of Malagón

\section{Estudios y comentarios}

951 Serafín Olcoz Yanguas

Apostilla al estudio Influencia de las redes nobiliarias en la expansión cristiana del siglo XII: el caso de Soria (ETF, 33, 2020)

Notes on the Article The Influence of Aristocratic Networks on the Christian Expansion of the Twelfth Century. The Case of Soria $(E T F, 33,2020)$

\section{Libros $\cdot$ Books}

969 CASTRIllo CASAdo, Janire, Las mujeres vascas durante la Baja Edad Media (María Jesús Fuente)

973 Crónica del rey Juan II de Castilla. Minoría y primeros años de reinado (I406I420). Garcia, Michel (edición y estudio) (Víctor MuÑoz Gómez)

981 Da Silva, Marcelo Cândido, História Medieval (Diego Carlo Améndolla SPÍNOLA)

987 Galende Díaz, Juan Carlos y Ávila SeoAne, Nicolás, El rodado regio hispánico. Fernando III de León y Castilla (I23O-I252) (MAURicio Herrero JIMÉNEZ)

989 GARcía IzQuiERdo, Iván, Frontera, fuero y concejos. El valle del Riaza en la Edad Media (siglos VIII-XII) (CARLOS BARQUERO GOÑI)

993 García IzQuierdo, Iván y Peterson, David (coords.), Camino y Señorío. Obra selecta de Luis Martínez García (Enrique Cantera Montenegro) 
995 González Paz, Carlos Andrés, O Bispado de Mondoñedo na Idade Media. Territorio, comunidade e poder (ENRIQue CANTERA Montenegro)

997 López Martínez, Amalia, Minutarios notariales de Estevo Pérez (Ourense, siglo XIV) (José Miguel López Villalba)

999 Miranda García, Fermín y López de Guereño Sanz, María Teresa (eds.), La muerte de los príncipes en la Edad Media. Balance y perspectivas historiográficas (ANA Echevarría Arsuaga)

1003 Motis Dolader, Miguel Ángel, Vivencias, emociones y perfiles femeninos. Judeoconversas e Inquisición en Aragón en el siglo XV (ANA EcheVARRía ArSUAGA)

1007 Solórzano Telechea, Jesús Ángel y Martín Pérez, Fernando (coords.), Rutas de comunicación marítima y terrestre en los reinos hispánicos durante la Baja Edad Media. Movilidad, conectividad y gobernanza (ENRIQUe José Ruiz Pilares)

1013 Torre, Sandra de la - Etxeberria, Ekaitz - Díaz de Durana, José Ramón (coords.), Valer más en la tierra. Poder, violencia y linaje en el País Vasco bajomedieval (EnRIQue CANTERA Montenegro)

1015 TRIllo SAN José, Carmen, La Vega de Granada a partir de documentación árabe romanceada inédita (I457-I494). Estudio, edición e índices (INMACULADA GONZÁlez SopeÑA)

1019 Val Valdivieso, M. ${ }^{a}$ Isabel - Villanueva Zubizarreta, Olatz (Coords.), Pero Ansúrez. El conde, su época y su memoria (Enrique CANTERA Montenegro)

1021 Villanueva Morte, Concepción y Fernández de Córdova Miralles, Álvaro, El embajador Claver. Diplomacia y conflicto en las «Guerras de Italia» (I495-I504) (ENRIQUe CANTERA MONTENEGRO)

1023 Normas de publicación · Authors Guidelines 


\section{ARTÍCULOS · ARTICLES}

\section{VOLUMEN I}





\title{
PELIGROS, INSEGURIDADES \\ Y PROBLEMAS DEL VIAJERO VISIGODO
}

\section{DANGER, LACK OF SAFETY AND PROBLEMS FOR THE VISIGOTHIC TRAVELLER}

\author{
Patricia A. Argüelles Álvarez \\ Recepción: 2020/09/30 · Comunicación de observaciones de evaluadores: 2020/10/20 . \\ Aceptación: 2020/10/28 \\ DOI: https://dx.doi.org/10.5944/etfiii.34.2021.28413
}

\begin{abstract}
Resumen
Las siguientes páginas ofrecen una visión de conjunto sobre las preocupaciones que el viajero tardoantiguo sufriría a la hora de emprender un viaje. Los caminos estaban llenos de problemas, ya fuera por la dureza de las jornadas o por posibles ataques violentos. A través del análisis de fuentes escritas, y prestando particular atención a la hagiografía medieval y al examen de la regulación viaria tardorromana, descubrimos la necesidad de proteger al viajero mediante la codificación de delitos que castigasen a los delincuentes. Aun así, tal y como reflejan las fuentes, no se erradicará dicha situación, pues existen numerosos ejemplos de salteadores de caminos que hacían peligrar la seguridad del viajero visigodo.
\end{abstract}

\section{Palabras clave}

Bandidos; salteadores; peligros; problemas; viajes; tardoantigüedad; visigodos.

\section{Abstract}

The following pages present an overview of the concerns that late-Antiquity travellers suffered when embarking on a journey. The roads were full of problems; whether they be the harshness of the trip or possible violent attacks to which they were exposed. Through the analysis of written sources, with special attention given to medieval hagiography and late-Roman road regulations, we will reveal the need for traveller protection through the codification of crimes and the

\footnotetext{
1. Universidad de Salamanca. C.e.: parguelles@usal.es

Grupo de investigación ATAEMHIS. Trabajo realizado en el marco del proyecto: Formación y dinámica de los espacios comunales ganaderos en el Noroeste de la Península lbérica medieval: paisajes e identidades sociales en perspectiva comparada. HAR2016-76094-C4-4-R.
} 
punishment of wrongdoers. Even so, as the sources demonstrate, this situation was not eradicated as we find persistent examples of bandits on highways making them unsafe for the Visigothic traveller.

\section{Keywords}

Bandits; Highwaymen; Danger; Problems; Travels; Late Antiquity; Visigoths. 


\section{INTRODUCCIÓN²}

En el 409 con la llegada a Hispania de vándalos, alanos y suevos, el poder central romano se desintegrará provocando el fin de la historia de Roma para, así, dar paso a una nueva configuración de gobierno. A consecuencia de ello, las ciudades más aisladas necesitarán rutas transitables alternativas a los grandes ejes viarios que facilitaran las relaciones entre los territorios. De ahí que estas antiguas vías secundarias vean prolongado su uso post-romano para favorecer los accesos del tránsito de viajeros y mercancías, siendo un escenario idóneo para la actividad delictiva de las bandas de salteadores3. Las Antiquae del Liber Iudiciorum reflejan el interés por amparar la seguridad viaria y su mantenimiento, si bien no sabemos hasta qué grado se aplicó esta normativa ${ }^{4}$. Lo que sí está claro es que los caminos heredados de Roma, con la llegada visigoda se encontraban acondicionados de manera desigual5, estando algunos de ellos en un estado más aceptable que otros que necesitaban una intervención en la mejora de sus infraestructuras ${ }^{6}$.

Como ya hemos hecho referencia con anterioridad, este nuevo contexto creado tras la desaparición del ya debilitado poder imperial será un marco idóneo para los ataques de bandidos y salteadores de caminos. Situación que vendrá propiciada por una atmósfera de descontento y malestar, no solo entre esclavos y libertos, sino también entre hombres libres de clases bajas ${ }^{7}$. La delincuencia se manifiesta entonces como expresión de rebeldía y protesta de este estrato social

2. Abreviaturas utilizadas: Ad Dem. = Ad Demetrianum; Braul=Braulio de Zaragoza; Brev= Breviario de Alarico o Lex Romana Visigothorum; CE= Codex Euricianus; $C T h=$ Codex Theodosianus; Con. Tol= Concilio de Toledo; D= Digesto; Hid= Hidacio; Greg. Tur= Gregorio de Tours; HW= Historia Wambae Regis; Laur. = San Laureano; LV= Lex Visigothorum o Liber ludiciorum; N Maj.= Novelas de Mayoriano; Sirm= Constitutiones Sirmondianae; SPE= Santos Padres Españoles; ss= Sulpicio Severo; vF= Vita Fructuosi; vM= Vida San Martín; vsPM= Vida de los Santos Padres de Mérida.

3. En el mundo romano las vías principales estaban a disposición de los movimientos del ejército, estando en la mayor parte de los casos los caminos secundarios (más incómodos) o las rutas marítimas (más rápidas) accesibles a los viajeros: ARCE, Javier: Bárbaros y romanos en Hispania 400-507 A.D. Madrid, Ed. Marcial Pons, 2007, p. 271. Sobre Roma y la organización viaria, véase LAURENCE, Ray: «The meaning of roads: a reinterpretation of the Roman Empire», en KuUliala, Jenni y Rantala, Jussi (eds.), Travel, pilgrimage and social interaction from Antiquity to the Middle Ages, London, Ed. Routledge, 2020, pp. 28-41.

4. Pese a tener constancia legislativa de una regulación de mantenimiento viario (cTh.8.5; 16.2.1.; N. Maj. 4.3, LV.VIII.4.25), no todos los autores están de acuerdo en que existió una actuación de mejora y acondicionamiento de los viarios romanos por parte de los monarcas visigodos: KARR, Karen Eva: «A Changing world-African Slip in Roman and Visigothic Baetica», en FERrEIRo, Alberto (ed.): The Visigoth studies in culture and society, Leiden-Boston-Köln, Ed. BRILL, 1999, P. 232. Sobre el régimen jurídico de las vías, véase PONTE, Vanessa: Régimen jurídico de las vías públicas en el derecho romano, Madrid, Ed. Dykinson, 2007.

5. Contradiciendo la teoría de KARR, ARCE indica que el sistema de caminos tardoantiguo era «aceptablemente adecuado», pese a las dificultades del momento tras el fin del Imperio Romano: ARCE, Javier: Bárbaros y romanos en Hispania 400-507 A.D., pp. 269-270.

6. En el año 399 se hace una llamada obligada a la colaboración de cualquier hombre del Imperio en la conservación viaria; así pues, el Código teodosiano introduce la idea de que el uso comunitario de los caminos supone asimismo una obligación grupal en su conservación (CTh.15.3): edición consultada para estas y sucesivas citas, Codex Theodosianus (ed. T. Mommsen y P. M. Meyer) 2 vols. Berlín: Weidmann, 1905.

7. PÉrez, Dionisio: «Problemas sociales del reino visigodo de Toledo», Studia Historica, Historia Antigua 1 (1983), pp. 105-117; García, Luis A.: Historia de España visigoda, Madrid, Ed. Cátedra, 1989, pp. $249-250$. 
más popular ${ }^{8}$. Así pues, la criminalidad, lacra ya presente durante el mundo antiguo, se arraiga como uno de los principales problemas a los que el viajero tendrá que hacer frente. Parece que el pillaje, los saqueos y los robos infestaron los caminos, siendo especialmente abundantes en los siglos vi - vil. La preocupación por esta situación queda de manifiesto en la dura regulación jurídica que aspirará a atajar este problema infundiendo un temor hacia el poder judicial9.

En este trabajo no solo abordaremos datos relevantes respecto a las acciones de pillaje en los caminos, sino que también pretendemos profundizar en otros inconvenientes que surgirían durante el viaje como, por ejemplo, la dureza propia del deformado firme viario, el alojamiento, los transportes o las largas distancias bajo las adversas condiciones climáticas. Todo ello nos hace pensar que planear un viaje no resultaba nada placentero.

Desde el mundo antiguo se constatan los problemas de la violencia ligada al viaje. Así pues, en el siglo in el obispo Cipriano de $\operatorname{Cartago}^{\mathrm{IO}}$ manifestaba el inconveniente latente de encontrar posadas a pie de un camino sitiado por ladrones, así como la gran probabilidad de caer en emboscadas, en especial en zonas montañosas ${ }^{\text {II }}$. Por ello, la importancia de conocer hospedajes de confianza era fundamental pues, en general, estas construcciones se habían convertido en lugares de corrupción e indignidad, donde la clientela principal era las factiones de latrones y vagabundos ${ }^{12}$.

Posteriormente, en la tardoantigüedad, con la aparición del viaje por motivos religiosos, la Iglesia fundará hospitales de peregrinos con la intención de dar cobijo a los viajeros ${ }^{13} y$ ofrecerles atención médica ${ }^{14}$. Se entiende que

8. GARCíA, Luis A.: El fin del reino visigodo de Toledo: decadencia y catástrofe: una contribución a su crítica, Madrid, Universidad Autónoma de Madrid, 1975, p. 75.

9. Ulpiano será pionero en crear una normativa imperial contra los bandidos en su tratado de officio proconsulis: «... nam et sacrilegos, latrones, plagiaros, fures conquirere debet et prout quisque deliquerit, in eum animaduertere, receptoresque eorum coercere, sine quibus latro diutius non potest» (D. I.18.13). Edición consultada, Cuerpo del derecho civil romano. T. III. Digesto (traducción y compilación I. García del Corral). Barcelona: [J. Molinas, ed.], 1897.

10. Cipriano de Cartago: Cartas (Ma ${ }^{a}$. L. García Sanchidrián, Introducción, traducción y notas). Ed. Gredos, $\mathrm{n}^{\circ} 255$, Madrid, 1998. pp.334-335.

11. Sobre ladrones y bandidos de caminos en el Imperio Romano, véase RuIz, Alicia: «Viajes y prácticas culturales en las provincias romanas de Hispania y la Galia» en IGLesIAS, José Manuel y RuIz, Alicia (eds.), Viajes y cambios de residencia en el mundo romano, Santander, Universidad de Cantabria, 2011, pp. 203-204, y sobre viajes en el mundo romano en general, IGLESIAS, José Manuel y RuIz, Alicia (eds.): Op. cit.

12. Cipriano de Cartago: carta 68; Ad Dem. XI, 1-17 en Cipriano de Cartago, Cartas (Mª. L. García Sanchidrián, Introducción, traducción y notas). Ed. Gredos, $n^{\circ}$ 255, Madrid, 1998. En época imperial y tardía existió la obligación de dar hospitium. La regulación se acentúa a finales del siglo IV y principios del siglo $\mathrm{V}$ para evitar desmanes propios en el hospitium. Sobre este tema, véanse ARCE, Javier: «El Cursus publicus en la Hispania tardorromana», en Actas del Simposio sobre la red viaria en la Hispania romana, celebrado en Zaragoza del 23-27 de Septiembre de 1987, Zaragoza, 1990, pp. 38-39; JıMÉNEZ, Jesús: «Hospedajes para viajeros en el Imperio romano», en MoRÈrE, Nuria, (coord.), Viajes en el Mediterráneo antiguo, Madrid, Editorial Universitaria Ramón Areces, 2009, pp. 161-181; GonZALbeS, Enrique: Viajes y viajeros en el mundo antiguo, Cuenca, Universidad de Castilla- La Mancha, 2003, pp.110-111; Bravo, Gonzalo: «La hospitalitas tardorromana: ¿tradición o innovación?» en BRAVo, Gonzalo y GonZÁLEz, Raúl (eds.), Ver, viajary hospedarse en el mundo romano. Madrid, Ed. Signifer, 2012, pp.205-220.

13. Díaz, Pablo C., Martínez, Clelia y SANZ, Francisco Javier: La Hispania tardoantigua y visigoda, Historia de España, n V, Madrid, Ed. Istmo, 2007, p. 547.

14. Szabŏ, Thomas: «Les dangers du voyage au Moyen Age. Problèmes et solutions», Siècles, Cahiers du centre d'histoire-Espaces et cultures 25 (2007), p. 60. 
este sería un formato de alojamiento mucho más seguro que el de las antiguas posadas romanas.

No cabe duda de que el tema del bandidaje, la inseguridad y los problemas derivados de los movimientos a larga distancia, así como la falta de infraestructuras durante el período del fin del mundo antiguo, han suscitado mucho interés entre los investigadores. Es abundante la producción científica relacionada con los viajes en la antigüedad; cabe citar, por ejemplo: Viajes y cambios de residencia en el mundo romano ${ }^{15}$, editado por J.M. Iglesias y A. Ruiz; el trabajo Viajes en el Mediterráneo antiguo ${ }^{16}$, de N. Morère; o el homenaje a Hèléne Guiraud, Voyages en Antiquitét7, editado por H. Jacquet-Rimassa y C. Nadal. También pueden ser citadas, entre otras obras, la publicación de G. Bravo y R. González, Ver, viajary hospedarse en el mundo romano, o la reciente publicación editada por J. Kuuliala, Jenni y J. Rantala, Travel, pilgrimage and social interaction from Antiquity to the Middle Ages. Igualmente son muy abundantes los trabajos sobre viajes en la tardoantiguedad vinculados a Oriente, como el estudio de C. Brélaz ${ }^{18}$ sobre $L a$ sécurité publique en Asie Mineure sous le Principat (I $I^{e r}-I I I^{\text {ème }}$ S. ap. J.-C.) y, en particular, al peregrinaje, como la edición de F. Marco, F. Pina y J. Remesal sobre Viajeros, peregrinos y aventureros en el mundo antiguo ${ }^{\mathrm{I}}$.

Sobre el tema en particular del bandolerismo y los peligros de los viajeros para el caso hispano, destaca el escrito de H. J. Diesner, trabajo muy bien informado que ha servido de inspiración a estas páginas ${ }^{20}$, junto a la publicación de E. Thompson sobre Peasant Revolts in Late Roman Gaul and Spain, ${ }^{2 \mathrm{y}} \mathrm{y}$ otros de temática similar, como el redactado por V. Neri, I marginali nell' Occcidente tardoantico. Poveri, «infames» e criminali nella nascente società cristiana ${ }^{22}$. En relación con la regulación legislativa visigoda que examinamos en este trabajo también ha sido fundamental B. Pottier ${ }^{23}$, autor de uno de los pocos trabajos existentes que abordan las inseguridades europeas en los viajes de los siglos IV- v. Todo ello forma el estado de la cuestión clave para desarrollar este estudio.

Por otro lado, este estudio se completa con el análisis de fuentes no solo legislativas, como el Codex Theodosianus, el Codex Euricianus o la Lex Visigothorum,

\footnotetext{
15. Iglesias, José Manuel y RuIz, Alicia (eds.): Op. cit.

16. Morère, Nuria, (coord.): Viajes en el Mediterráneo antiguo.

17. JacQuet-Rimassa, Pascale, Hoffmann, Genevière, NADAL, Eléonore y CaSsimatis, Hélène: Voyages en Antiquité. Mélanges offerts á Hélène Gruiraud, Pallas, Revue d'Études Antiques, 76, 2008.

18. BréLAZ, Cédric: La sécurité publique en Asie Mineure sous le Principat (ler-III ème s. ap. J.-C.). Bassell, Schawabe Verlag, 2005.

19. Marco, Simón, Francisco, Pina, Francisco y Remesal, José (eds.): Viajeros, peregrinos y aventureros en el mundo antiguo, Barcelona, Publications i Editions de la Universitat de Barcelona, 2010.

20. DIESNER, Hans- Joachim: «Bandas criminales, bandidos y usurpadores en la España visigoda», Hispania Antiqua VIII (1978), pp. 129-142.

21. Thompson, Edward Arthur: «Peasant Revolts in Late Roman Gaul and Spain», Past \& Present 2 (1952), pp.11-23.

22. NeRI, Valerio: I marginali nell' Occidente tardoantico. Poveri, «infames» e criminali nella nascente società cristiana, Bari, Edipuglia, 1998.

23. POTTIER, Bruno: «Les dangers du voyages: banditisme et insécurité sur les routes au IVe et Ve siècles», Antiquité Tardive 24 (2016), pp. 137-148.
} 
sino también las hagiografías de religiosos como Valerio del Bierzo, Fructuoso de Braga o Braulio de Zaragoza ${ }^{24}$, entre otras referencias.

\section{PELIGROS: LA VIOLENCIA}

La abundante ola de crímenes acaecidos en los caminos italianos en la segunda mitad del siglo IV condujo a una estricta regulación imperial que comprometía a todos los territorios bajo control romano, con la intención de identificar y castigar estos actos al margen de la ley. Los preceptos se tornaron tan estrictos que se llegó al extremo de prohibir la posesión de varios caballos, pues se presuponía que la tenencia de estos animales facilitaba el tránsito por los caminos ${ }^{25}$. Asimismo, esta disposición atacaba directamente a los pastores, quienes en ocasiones eran identificados como ladrones ${ }^{26}$. Por tanto, era patente la necesidad de buscar culpables a los frecuentes crímenes ${ }^{27}$ e incluso de castigar a aquellos cómplices que entregaban provisiones a estas bandas delictivas ${ }^{28}$.

El problema de la inseguridad durante el tránsito por las antiguas calzadas se pone de manifiesto durante toda la historia de Roma, tanto en periodos convulsos como de paz $^{29}$. La imposibilidad de controlar este problema derivó en la decisión de dejar la vigilancia y protección del viajero en manos de los militares stationari $^{30}$, los cuales eran responsables de tareas tan distintas como combatir robos en los caminos, cobrar peajes o detener la fuga de prisioneros. Durante la tardoantiguedad observamos cómo con Chindasvinto y Recesvinto se acentúa una política militar, lo que implicaba un fuerte dominio territorial a modo de vigilancia, control y defensa. Se asocia a esta nueva situación político-administrativa la existencia de puntos de control, a modo de torres o castillos jalonando las vías ${ }^{31}$.

24. Díaz y Díaz, Manuel C.: La vida de san Fructuoso de Braga. Estudio y edición crítica, Braga, 1974; Díaz y Díaz, Manuel C.: Valerio del Bierzo. Su persona. Su obra, León, Centro de Estudios e investigación «San Isidoro», 2006; BRAULIO De Zaragoza, Isidoro De Sevilla, Epistulae, Confessio uel professio ludaeorum ciuitatis Toletanae (eds. R. Franco Miguel, J.C. Martín-Iglesias). Corpus Christianorum, Series Latina (CCSL 114B), Turnhout, Brepols, 2018.

25. cTh.9.30.2; 30.5 .

26. CTh.9.31.1; La ley del 409: «Ne pastoribus dentur filii nutriendi» regula el bandidaje que «ejercían los pastores trashumantes» (cTh.9.31). Sobre este tema véase SÁNCHEZ, Jesús: «¿Bandidos lusitanos o pastores trashumantes?», Hispania Antiqua XXI (1997), pp. 69-92.

27. D. IX.2.11.

28. CTh.9.42.22; 9.42.24.

29. VAN TILBURG, Cornelis: Traffic and congestion in the Roman Empire, London, Ed. Routledge, 2007, p.67; SHAW, Brent: «Bandits in the Roman Empire», Past \& Present 105 (1) (1984), pp. 3-52.

30. Sobre los stationarii véase Fumrmann, Christopher: Policing the Roman Empire, New York, Ed. Oxford University Press, 2012, pp. 250-251; PetracciA, María Federica: Gli «stationarii» in età imperiales, Roma, Ed. Serta Antiqua et Medievalia, III, 2001.

31. AjA, José Ramón: «Cantabria en la Antigüedad tardía», en AjA, José Ramón, CISNEROS, Miguel y RamíreZ, José Luis (coords.), Los cántabros en la antigüedad: la historia frente al mito, Santander, Universidad de Cantabria, 2008, p. 214; DíEz, Carmen: «Hacia la Edad Media: ¿advenimiento de nuevas formas de organización social y territorial?», en AJA, José Ramón, Cisneros, Miguel y Ramírez, José Luis (coords.), Op. cit.., p. 266; GarcíA, Luis A.: Historia de España visigoda, p. 297. 
En este contexto de la tardoantiguedad nos encontramos con los textos de Hidacio, quien alude a los bagaudas en el conventus Bracarensis ${ }^{32}$. Los cambios sociales y políticos tras la caída del Imperio son palmarios, al aparecer nuevos organismos para la gestión territorial. En el citado texto de Hidacio también se menciona a los temidos latrones, que ya actuaban de manera dispersa por los caminos de Braga. En este caso se aludía a oportunistas y gentes sin recursos que aprovechaban la situación de debilidad sueva. Este ejemplo en particular, analizando la terminología de Hidacio, ha de ser interpretado de manera distinta a posibles revueltas reivindicativas de la aristocracia o al propio papel de los citados bagaudas ${ }^{33}$. Por tanto, como ya adelantábamos, el carácter revolucionario y al margen de la ley de estos grupos no ha de confundirse con los saqueadores de caminos. Si bien, las asociaciones de latrones podrían estar compuestas por gentes de clases bajas y cuerpos militares ${ }^{34}$ que, tal y como más adelante indicase Braulio

32. Hid. Chron, 172. P.C. Díaz considera que este fenómeno de violencia vino dado ante la desaparición del poder suevo y la falta de una autoridad equivalente Díaz, Pablo C.: El reino Suevo 411-585. Madrid, Ed. Akal, 2011, p. 149.

33. Sobre bagaudas, véanse Bravo, Gonzalo.: «Acta bagaudica (I): sobre quiénes eran «bagaudas» y su posible identificación en los textos tardíos». Gerión, 2, (1984), pp. 251-264; Bravo, Gonzalo: «Los Bagaudas: vieja y nueva problemática». Actas del 1er. Congreso Peninsular de Historia Antigua. Santiago de Compostela, 1-5 julio 1986, Vol. 3, (1988), pp. 187-196; GarcíA, Luis A.: El fin del reino visigodo de Toledo: decadencia y catástrofe: una contribución a su crítica, pp. 64-98; NeRI, Valerio: I marginali nell' Occcidente tardoantico. Poveri, «infames» e criminali nella nascente società cristiana, Bari, Edipuglia, 1998, pp. 400-417; Collıns, Rogers: La España visigoda 409-711, Barcelona, Ed. Crítica, Traducción por M. García Garmilla, 2004, pp. 22, 33, 60; Díaz, Pablo C., Martínez, Clelia y SANz, Francisco Javier: La Hispania tardoantigua y visigoda, pp. 327-328; CLIFFORD, E. Minor: «'Bagaudae' or 'Bacaudae'?», Traditio, 31 (1975), pp. 318-322; CLIFfORD, E. Minor: «Bacaudae: a Reconsideration», Traditio 51, (1996), pp. 297-307.

34. El Código teodosiano adelanta la idea de que aquellos militares que desertasen para incorporarse a bandas de delincuentes no tendrían escapatoria a la severidad de la aplicación legal (cTh. 8. 7.19; 8).

De igual forma, Hidacio alude a la expedición militar comandada por Teuderico Il que llevaría a la derrota de Requiaro. Este hecho derivó en que la escasa presencia militar sueva se aliara en un intento de reconstruir una monarquía militar nueva, organizada en bandas ocupadas en el pillaje de manera fugitiva por todo el Conventus Bracarensis:' en Hid. Chron, 186 [179] «In conventus parte Bracarensis latrocinantum depredatio perpetratur...». En la edición de W. Burgess, 179, p. 108 nota 172. Véase también GARCíA, Luis A.: España, Siglo V. La Monarquía goda Balta y la Diócesis de las Españas, Madrid, Real Academia de la Historia, 2017, p.98.

Un ejemplo de una fuerte ofensiva bagauda, que arrasó los territorios de Caesaragusta e llerda, fue la del año 449, narrada también por el propio Hidacio en Hid. Chron, 142. Teodorico arrasa la región de Zaragoza con Basilio y, tras entrar con artimañas en Lérida, captura prisioneros: en HIDACIO, The Chronicle of Hydatius and the Consularia Constantinopolitana, (ed. with English translation by R.W. Burgess), Oxford, Clarendon Press, 1993. Véase BARENAS, Ramón: La articulación eclesiástica del Valle Medio del Ebro y su área de influencia (ss. III-VIII), Tesis doctoral, Universidad de La Rioja, Inédita, 2015, p. 90, nota 41. Las consecuencias de la ofensiva del 449 no solo fueron materiales, sino que también se prendieron cautivos durante el paso de expediciones militares por un territorio. Ello ponía en peligro a los lugareños y sus bienes, y deterioraba las condiciones de las antiguas calzadas romanas, de las que no sabemos hasta qué grado los visigodos se preocuparon por acondicionar. Por otro lado, Rutilio Namaciano en el año 417, cuando viaja en dirección a la Galia, nos informa de que la vía Aurelia tenía el pavimento deteriorado a consecuencia de las devastaciones visigodas, y que, según él, esos deterioros eran casi más molestos para el viajero que los propios bandidos (1.37-38). Rutilio NAmACIANo, De reditu suo. El retorno - Geógrafos latinos menores (introducción, traducción y notas de A. García-Toraño Martínez). Madrid, Ed. Gredos, 2003. Por tanto, no solo las aldeas, sino también los recintos fortificados que surgen desde el siglo V (a modo de control territorial) cerca de la red de calzadas (resultando más visibles), estarán amenazados, pues concentraban gran número de población y recursos. Si bien los viajes militares son un tema aparte de esta investigación, queda patente que el problema que generaba el paso de una expedición por un territorio parece que fue algo que preocupó a los gobernantes visigodos pues, como indicamos anteriormente, los pueblos que quedaban al pie de los caminos sufrían el saqueo de las expediciones. La inseguridad que era causada por las milicias y tenía como víctimas a los aldeanos, intentó ser controlada por la Lex Visigothorum: «De aquellos que, yendo en una expedición, intenten tomar o saquear algo». Así pues, el precepto obligaba a restituir lo robado y castigaba con 150 azotes al infractor. Según apunta la ley, la preocupación se basaba en no empobrecer las provincias del reino permitiendo las depredaciones de 
de Zaragoza ${ }^{35}$, llegaban a controlar todo un extenso territorio bajo un entramado de poderes locales ${ }^{36}$.

Retomando el tema de investigación de este estudio sobre peligros e inseguridades, volvemos al caso relativo a actos violentos a manos de bandidos. El obispo Braulio de Zaragoza alude a las desgracias que en su tiempo (s. vil) le había tocado vivir durante sus viajes, como las tempestades y la inseguridad existente en el entorno de Zaragoza ${ }^{37}$. El grado de peligrosidad sería notorio, y parece ser la que la gente habría dejado de viajar por el temor de enfrentarse a «ladrones», que estarían en los caminos perturbando el tránsito hacia Valencia.

También resultan significativas las alusiones de Valerio del Bierzo ${ }^{38}$, contemporáneo a Braulio de Zaragoza, sobre el riesgo de iniciar un desplazamiento por el territorio hispano. Estas ideas se presentan en relación con la intención que tenía Valerio de instalarse en el monasterio leonés de Rufiana. Este santo se quejaba de que este monasterio estaba demasiado apartado y el acceso era un camino, ya por aquel entonces «antiguo». El citado camino al que alude Valerio que, tal y como transmite en sus textos, recorrió en varias ocasiones, era de circulación complicada pues era laberíntico y se dibujaba entre rocas. Reveladora es la reflexión de Valerio 39 apuntando a que los hombres solían viajar de uno en uno dadas las malas condiciones del camino, y ello suponía estar totalmente indefenso ante posibles saltadores.

las huestes en «...Cuius rei exactionem provinciarum comites vel iudices aut vilici studio suo non morentur inpendere, quia provincias nostras non o volumus hostili predatione vastari...» (LV. VIII.1.9), edición consultada para estas y siguientes citas en Liber ludiciorum (estudio preliminar de R. Ramis Barceló; traducción y notas de P. Ramis Serra y R. Ramis Barceló). Madrid: Agencia Estatal Boletín oficial del Estado, 2015. Véase también VALVERDE, María Rosario: Los viajes de los reyes visigodos de Toledo (531-711), Madrid, Ed. La Ergástula, 2017, p. 93.

En los textos del obispo Gregorio de Tours encontramos un episodio del año 584 protagonizado por la comitiva que acompañaba a la princesa franca Rigunta hacia Toledo, para su desposorio con Recaredo. Narra Gregorio que este séquito usurpó todos los bienes de las gentes que encontraba a su paso (ganado, cosecha, vides...): Greg. Tur. Hist. Franc. 6.45 «...per quam via tanta spolia tantaequae predae factae sunt...» en GREGORIO DE TOURS. Historianum libri X (eds. B. Krusch, W. Levison, M.G.H). ss. 1. Hannover, 1888.

Sobre el avituallamiento de las tropas durante las expediciones, parece que las tropas viajaban ligeras de provisiones, por lo que el saqueo y el latrocinio sería algo común, en especial cuando no existía preparación logística y era una campaña improvisada, tal y como fue el caso de Wamba en su expedición a la zona vascona: VALVERDE, María Rosario: Los viajes de los reyes visigodos de Toledo (531-711), pp. 200-207. Es por ello, que los soldados eran equiparados a los propios bandidos en HW. 10.18 en JULIÁN DE TOLEDO. Historiae de Wambae regis Gothorum Toletani expeditione. Monumenta Germaniae Historica, T.5. Hannover, 1910. Si bien, claro está, sus acciones eran debidas a las necesidades propias de la expedición y su fin último sería la movilización según las estrategias de campaña, nada que ver con los propios ladrones, cuya actividad principal era causar el terror en los caminos.

35. Véase nota 37.

36. Díaz, Pablo C., Martínez, Clelia y Sanz, Francisco Javier: La Hispania tardoantigua y visigoda, p. 329.

37. Braul., Ep. 24: «quoniam regiones nostrae homines pergere illuc pavent ob latrones» en BRAULIO DE ZARAGOZA, IsIdORO dE SEVILLA Epistulae, Confessio uel professio ludaeorum ciuitatis Toletanae (eds. R. Franco Miguel, J.C. MartínIglesias). Corpus Christianorum, Series Latina (CCSL 114B), Turnhout, Brepols, 2018. Carta fechada en el 641 según GARCíA, Luis A.: El fin del reino visigodo de Toledo: decadencia y catástrofe: una contribución a su crítica, p. 75.

38. Sobre la figura de este santo se han consultado las ediciones de Díaz y Díaz, Manuel C.: Valerio del Bierzo. Su persona. Su obra, León, Centro de Estudios e investigación «San Isidoro», 2006 y también FrIGUETTO, Renan: Valério do Bierzo. Autobiografia, La Coruña, Serie Trivium, 2006.

39. Valerio del Bierzo. Item quod de superioribus Querimoniis Residuum sequitur (1) en DíAz y Díaz, Manuel C.: Valerio del Bierzo. Su persona. Su obra, León, Centro de Estudios e investigación «San Isidoro», 2006. 
Ladrones y salteadores de caminos vuelven a ser protagonistas del texto valeriano en relación con varias disputas acontecidas en el monasterio. Valerio padeció varios problemas con un presbítero que pretendía hacer la vida imposible al santo, y es que este otro clérigo encargó a «malvados y crueles bandidos» que humillasen a Valerio ${ }^{40}$.

Encontramos más referencias a los viajes de Valerio del Bierzo en otro pasaje en el que se menciona nuevamente a los ladrones. En esta historia el protagonista era Juan el diácono, quien habría servido en el monasterio de Rufiana. Parece ser que el tal Juan tenía un mulo y esto era motivo de envidia de otro monje más anciano del monasterio. Este texto narra el momento de un asalto, poniéndonos en el contexto de que otro clérigo habría contratado a unos maleantes para que robasen a Juan en el camino y de esta manera el mulo sería para el avaro anciano. Aparece en el texto la «ultio diuina» ya que, por la gracia de Dios, el animal fue liberado y retornó sano al monasterio. Parece ser que Juan tuvo un final más amargo, pues murió tiempo después a manos de los monjes. Las consecuencias del intento de robo del mulo se resolvieron gracias a la «venganza divina», que destruyó las cosechas de aquellos forajidos que, además, fueron asaltados por otros delincuentes, dejando de esta manera patente el poder divino para llevar a cabo la protección de sus fieles ${ }^{4 \mathrm{I}}$.

También para el s. vi Leandro de Sevilla, en sus reflexiones hacia el espíritu, la humildad humana y el buen camino para frenar a los arrianos, comparte sus preocupaciones al mencionar a los bandoleros (sin que este sea el tema principal de su argumento) en relación con que la posesión de bienes materiales no es necesaria, para el hombre, ya que esta atrae a los ladrones de caminos que buscan a viajeros cargados de oro y plata ${ }^{42}$.

Como vemos, la intimidación causada por bandoleros es un tema recurrente; así pues, cabe pensar que incluso al ser atacado por asaltantes, la víctima podría llegar a ser asesinada a manos de los propios ladrones, aunque quizás los malhechores pudiesen ser benévolos, mutilando y no asesinando a la víctima: «occisus

40. Valerio del Bierzo. Item Valeri narrationes superius memorato Patri notro Donadeo Ordo querimoniae Praefatio Discriminis (7). Este fragmento transmite la idea de que los bandidos no solo actuaban en los caminos para robar las pertenencias de los viajeros, sino que también podían trabajar como «matones» por encargo a cambio de una remuneración. 41. Valerio del Bierzo. Item Valeri narrationes superius memorato Patri notro Donadeo Ordo querimoniae Praefatio Discriminis (26) en DíAz y DíAz, Manuel C.: Valerio del Bierzo. Su persona. Su obra.

Las referencias sobre esta historia son contradictorias; así pues, además del relato anteriormente narrado, en la Item replicatio sermonum $(23,24)$ parece que Juan nunca ha vivido en Rufiana, sino que coincidió con Valerio en Castro Petrense y se ve obligado a separarse de este tras un ataque de bandidos. Una vez recuperado de los golpes propinados en el ataque, se reencuentra con Valerio, siendo asesinado al poco tiempo por campesinos del lugar. En ambas historias los bandidos aparecen como protagonistas del aciago futuro de Juan.

Los expertos proponen o bien la existencia de dos personas distintas, es decir dos Juanes, o la adaptación del propio Valerio de una misma historia, de acuerdo con que Juan el diácono no es un personaje real sino literario creado por Valerio tas la muerte de su discípulo Juan. Sobre este tema, véase MARTín, José Carlos: «¿Valerio en Compludo? Examen crítico de los opúsculos autobiográficos (CPL 1282-1284) y las visiones del más allá (CPL 1277-1279) de Valerio del Bierzo», Veleia 23 (2006), pp.331.

42. Domínguez del VaL, Ursicino: Leandro de Sevilla y la lucha contra el arrianismo. Madrid, Ed. Nacional, 1981, p. 444. 
a latronibus». Se insiste en el concepto de que salir vivo de un enfrentamiento con bandidos era una ventura ${ }^{43}$.

Distinto infortunio, que podía llevar también incluso a la muerte, era el cautiverio $^{44}$. En ocasiones las bandas de asaltantes llegaban a secuestrar al viajero, bien para quitarle sus bienes o bien para reclamar una recompensa ${ }^{45}$. Quizá la falta de textos que documenten los secuestros de viajeros en la Hispania visigoda pueda conducir a la idea de que el bandidaje occidental tardoantiguo estaba mucho menos organizado que el de grupos de bandidos orientales ${ }^{46}$, aunque no por ello se descartaría la idea de que en el territorio más occidental europeo existieran este tipo de acciones.

En el caso de las mujeres no contamos con relatos detallados de visigodas viajeras, aunque sabemos que Gregorio de Nisa, en el siglo V, manifestaba su malestar a propósito de las peregrinaciones femeninas. La justificación venía dada por la debilidad natural de la mujer y la obligación masculina de ayudarlas en su protección, cabalgadura, pasos difíciles, etc... ${ }^{47}$. Problema aparte sería lo inapropiado

43. Se documentan tres epígrafes romanos para Hispania en relación con la muerte a manos de salteadores. Las cronologías ofrecidas no son tardoantiguas, pero sí confirman que para el Principado la lucha contra el bandidaje era ya un problema cotidiano. Por un lado, contamos con un ejemplo republicano para el epitafio sepulcral documentado en Algodonales, Cádiz: Anée épigraphique AE 1982, 512: M(arci) Clodi Rufini an(norum) / xxIII [a]b(!) latroni/b(us) oc(c) isus est s(it) t(ibi) t(erra) I(evis), en GonzÁLEZ, Julián: «Interrex y occisus est ab latronibus», en J. Higueras Maldonado (coord.), Actas del I Congreso Andaluz de Estudios Clásicos (Jaén, 1981), Jaén, 1982, pp. 223-227. Otros casos sin cronología son, por un lado, el navarro CIL II 2968: Calaetus Eques/i f(ilius) annorum xx / a latronibus oc/cisus Acnon ma/ter d(e) p(ecunia) [s(ua)], sin una cronología propuesta hasta la fecha: Rodríguez, Antonio, Aquae Flaviae: I. Fontes epigráficas da Gallaecia meridional interior, Chaves, 1997, $\mathrm{n}^{\circ}$ 304, y por otro el ejemplo documentado en Requena, Valencia IRPV IV, 179: [-] lunius L(uci) lu-/ni flil(ius) Sosi/nai domo Gili/tanus h(ic) s(itus) e(st) / dolo [la]tron-/um manu o-/c(c)isus sum fili-/ us et generes / hoc mihi f(ecerunt) m-/onumentum. Véase también cita 53.

44. Referente al rapto y liberación de individuos en asaltos violentos, resulta interesante el rescate de cautivos recogido en la Regla Communis IX, en el que la Iglesia interviene en la redención de cautivos como gesto caritativo, quedando éstos bajo supervisión monacal: DíAz, Pablo C.: «Redimuntur captivi. A propósito de la Regula Communis IX», Gerión 10 (1992), pp. 287-293. Véase también la Regla de san Isidoro IV, XX y la Regla de san Fructuoso XX (SPE II) en Santos Padres Españoles II. San Leadro, San Fructuoso, San Isidoro. Reglas monásticas de la España visigoda. Los tres libros de las «Sentencias» (ed. Crítica bilingüe por J. Campos e I. Roca). Madrid, Biblioteca de Autores Cristianos, 1971. Así mismo, las legislaciones recogen cómo gestionar los actos derivados de un cautiverio (cTh. 5.7.2, Brev.V.5.2 en Codici Theodosiani. Legis Romanae Wisigothorum. Fragmenta ex codice palimpsesto Sanctae Legionensis Ecclesiae. Matriti: apud Ricardum Fe, Regiae Academiae Typographum, 1896, D. XLIX.15, D. XLIII.29.3, LV.V.4.21, LV.V.7.20, Sirm.16 en Codici Theodosiani. Lex romana Visigothorum. Fragmenta et Codice Palimpsesto (ed. Regia Historiae Academia hispana), New York, 1896.

45. Como hemos indicado, tenemos referencias epigráficas hispanas sobre la violencia que deriva en el asesinato de viajeros, si bien no hemos documentada ninguna alusión a secuestros para el caso del territorio visigodo. Quizá unas de las referencias más próximas al territorio hispano, geográficamente hablando, sea el ejemplo de la vida de San Martín de Tours. Sulpicio Severo informa de que San Martín, en su camino hacia la Panonia en el s. IV, encontró a unos ladrones cerca de los Alpes que le golpearon, maniataron y retuvieron; pero tras enzarzarse en una discusión teológica con uno de los malhechores, finalmente fue liberado. Se dice que convirtió al delincuente a la vida religiosa (ss. vM.5) en Sulpicius Severus: Vita Martini (ed. P. Burton), Oxford, 2017: 101.

46. Un ejemplo de secuestro y pago por liberación es narrado por Amiano Marcelino, aunque no en relación con un viajero si no a un tal Lepcis, que fue sacado extramuros de la ciudad para su cautiverio hasta recibir el pago por parte de su esposa y que finalmente fallecerá en los días siguientes $(28,6,14)$ : AmIANO MARCELINO. Historia (traducción por M. L. Harto Trujillo). Madrid, Ed. Akal, 2002.

47. Sobre viajes de peregrinaje y alguna referencia femenina, véanse DíAz, Pablo, C.: «El peregrino y sus destinos: los lugares de Cristo», en Marco Simón, Francisco, PINA, Francisco y RemesaL, José (eds.), Viajeros, peregrinos y aventureros en el mundo antiguo, Barcelona, Publications i Editions de la Universitat de Barcelona, 2010, pp. 241-266; Maraval, Pierre: Lieux saints et pelerinages d' Orient. Histoire et géographie. Des origines à la conquête árabe, Paris 1985 . 
que resultaba que las mujeres pernoctaran en las licenciosas posadas ${ }^{48}$. Al igual que los hombres, estas también podían sufrir el secuestro y cautiverio.

\section{OTROS PROBLEMAS E INSEGURIDADES}

No cabe duda de que la violencia ejercida por los salteadores de caminos se podría considerar uno de los principales peligros del viajero. No obstante, tal y como adelantábamos, los peligros eran numerosos. Una peripecia narrada por San Fructuoso en el s. viı nos presenta el problema de haberle confundido con un fugitivo. Así, nos cuenta que cuando hallándose cerca de Mérida, en dirección a Cádiz, un lugareño no reconoció sus hábitos y le atacó con improperios e incluso sufrió violencia física, pues creía que era un fugitivo ${ }^{49}$. El texto enfatiza en la oportuna aparición divina, pues Dios acudió en su ayuda, de forma que el asaltante, como poseído, terminó él mismo ensangrentado; mas el propio Fructuoso, como «santo varón», le restituyó la salud ${ }^{50}$, poniéndose así en evidencia que Dios ayuda a los buenos fieles ante cualquier problema. Está claro que este no es un ejemplo de robo o pillaje, pero sí que afirma la idea de que durante un viaje cualquier peligro podía acaecer, pues eran zonas de paso de maleantes y los propios locales se defendían ante un posible ataque.

La muerte podía ser algo natural, pero también, tal y como ya aludimos en el apartado anterior, podía ser provocada por los propios asaltantes ${ }^{51}$. A estos riesgos deberíamos sumar el peligro de las caídas, al andar por vías mal

48. Gregorio de Nisa, Epístola 2 en Gregorio De Nisa. Lettres (introduction, texte critique, traduction, notes et index por P. Maraval). Sources Chrétiennes, $n^{\circ}$ 363, Paris, 1990.

49. Aunque no fue el caso de Fructuoso, parece que no era raro encontrar clérigos vagando por caminos una vez expulsados de sus órdenes o por fuga voluntaria (SPE, II, Regla común XX) en Santos Padres Españoles II. San Leandro, San Fructuoso, San Isidoro. Reglas monásticas de la España visigoda. Los tres libros de las «Sentencias» (ed. Crítica bilingüe por J. Campos e I. Roca). Biblioteca de Autores Cristianos. Madrid, 1971. Tanto es así que en el año 683 el xIII Concilio de Toledo toma medidas contra aquellos que daban cobijo a estos religiosos que buscaban nuevas oportunidades (Con. Tol. XIII.9), en VIVES, José, Concilios visigóticos e Hispano-romanos, Vol. 1, Barcelona - Madrid, CSIC, 1963, pp. 429-230. Fuera del control eclesiástico, los ex clérigos pasaban a ser vagabundos o fugitivos y se veían obligados a errar como nómadas por los caminos junto a un elevado grupo de campesinos empobrecidos que también vagaban mendigando, siendo a veces difícil distinguir a estos dos grupos de los propios ladrones; sobre estas cuestiones, véase GARCíA 1989, p. 249.

El tema de los fugitivos fue un problema predominante en la legislación visigoda. Así, la Lex Visigothorum no solo regulaba el caso de clérigos, sino de todo tipo de individuos, independientemente de su condición social (LV. IX). Sobre Este Tema, Véase ISLA, Amancio: «Los fugitivos y el título sobre ellos del Liber ludicum», Arqueología y Territorio Medieval 8 (2011), pp. 113-124.

50. VF. 11 en DíAz y DíAz, Manuel C.: La vida de san Fructuoso de Braga. Estudio y edición crítica, Braga, 1974; Un testimonio más vago que la mencionada narración de Fructuoso acerca de la inseguridad del entorno de Mérida lo encontramos en el relato del obispo Fidel, en el siglo vII: «Fidel camina con los santos», cuando se narra el viaje de un sirviente al que envía a Caspiana (a 17 millas de Mérida), el cual, llegando de noche a la ciudad, no pudo entrar pues las puertas estaban cerradas (VSPM): Vida de los Santos Padres de Mérida (introducción, traducción y notas de I. Velázquez). Madrid, Ed. Trotta, 2008. La protección de la ciudad y el cierre de puertas puede asociarse a la seguridad de los ciudadanos y la existencia de delincuencia extramuros. Véase la nota 46. Véase también la edición de Vitae sanctorum patrum Emerentensium, (ed. A. Sánchez Maya). Corpus Christianorum, Series Latina 116, Turnhout, Brepols 1992.

51. Véase nota 43. 
acondicionadas ${ }^{52}$ o por pasos estrechos, es decir zonas de difícil orografía ${ }^{53}$, así como los problemas climáticos ${ }^{54} \mathrm{o}$ la aparición de fieras ${ }^{55}$.

Retornando a la vida de Fructuoso, localizamos otra historia de un viaje, en este caso junto al presbítero Benenato, recorriendo calzadas de la Lusitania a la Bética. En esta ocasión se tuvieron que enfrentar a la climatología, cuando durante el invierno les sorprendieron continuadamente los aguaceros y los ríos se desbordaron. Uno de los caballos que transportaba libros sagrados se hundió en un gran caudal, siendo milagroso que aquellos libros apareciesen secos ante el santo, una vez recuperados de las aguas ${ }^{56}$. Parecida es la historia del momento en que, una vez fundado el monasterio Peonense, en tierras galaicas, la tempestad del mar arrastró las barcas en las que debían viajar los discípulos, llevando a éstos a la máxima desesperación, solo contenida con la ayuda de Dios ${ }^{57}$. Las tormentas, el frío y la aspereza de los vientos también los padeció el propio San Millán, tal y como nos narra Braulio de Zaragoza, cuando ascendió por un pedregoso y arduo camino hacia el monte Distercio, donde se confinó durante cuarenta años ${ }^{58}$.

Parece que los riesgos fueron una constante en la vida de Fructuoso, pues son abundantes en sus relatos. En una ocasión su vida peligró al encontrarse en la vía con un cazador. Este episodio describe el momento en el que Fructuoso, vestido con una piel de cabra, se detiene para realizar sus oraciones. Un cazador le confunde con un animal, y sería la providencia divina la que, al levantar los brazos en alto en

52. Ya hemos aludido al viaje de Rutilio Namaciano en el año 417, cuando viaja en dirección a la Galia. Indica que el pésimo estado de las calzadas era igual de inconveniente que la posible aparición de ladrones (1.37-38). RUTILIO NAMACIANo, De reditu suo. El retorno - Geógrafos latinos menores (introducción, traducción y notas de A. García-Toraño Martínez). Madrid, Ed. Gredos, 2003.

53. El obispo Laureano de Sevilla se quejaba de que la Cristiandad estaba en peligro en el año 440 cuando, electo el pontífice León el Grande, las guerras y la irrupción enemiga dificultaban las reuniones eclesiásticas: «... por la dificultad de los caminos comenzaron a ser raras las juntas de los Obispos, hallando libertad la secreta perfidia, por ocasión de la perturbación pública y para la perversión de muchas almas...». Laur. Part. I. Lib. III, en LAUREANO DE OBISPO METROPOLITANO de SEVILLA Y MÁRTIR, Parte primera danse sus actas purgadas, y sostenidas contra las modernas impugnaciones (ed. D. Tello Lasso de la Vega), Sevilla, 1758, p.307. Sabemos de Laureano que sufrió martirio en Vatán a manos de Totila y ello, le llevó a la muerte en el 536. No obstante, el obispo de Arles atribuiría la muerte de Laureano a ladrones hispanos «a latrunculis Hispaniae ibídem decollatus est. Caput ejus, me jubente, Hispanlim deferunt», LaUreano de OBISPO Metropolitano de SEVILLA Y MÁRTIR, Parte primera danse sus actas purgadas, y sostenidas contra las modernas impugnaciones (ed. D. Tello Lasso de la Vega), Tomo I. Sevilla, 1758. p.267.

54. Amiano Marcelino detalla el peligro de caer por la ladera nevada durante un viaje (15.10.5). Otra anécdota se describe en la narración de los viajes del presbítero Orosio, cuando a comienzos del siglo V narra la noticia de un desastre naval durante el intento de cruzar el estrecho de Gibraltar, posiblemente en referencia al paso de un grupo visigodo comandado por Valia para llegar a territorio africano: Historias, VII 43, 10-12 y 15 en MARTínEZ, Pedro: El pensamiento histórico y antropológico de Orosio. Antigüedad y Cristianismo. Murcia, Universidad de Murcia, Monografías históricas sobre la antigüedad tardía, XIX, 2002, p. 54. Otro ejemplo lo encontramos en el XIV Concilio de Toledo del año 684 donde se aclara la necesidad de aplazar el concilio debido a que las heladas y el frío glaciar impidieron reunir a los miembros desde puntos tan dispersos, en Concilios visigóticos e Hispano-romanos, (ed. J. Vives), Vol. 1, CSIC, Barcelona - Madrid, 1963, pp.442-443. La propia Lex Visigothorum bajo mandato de Recesvinto aclara que solo problemas climatológicos como nevadas (compersio nivis) o desbordamientos de ríos (inundatio fluminis), eran causa justificada para «descartar las órdenes del rey». LV. II. 1.33.

55. Un poco más adelante describimos el encontronazo de san Fructuoso con unos cazadores a causa de una presa que éstos perseguían.

56. VF.12.

57. VF.7.

58. Braulio De Zaragoza, Vita Sancti Aemiliani, (ed. J. P. Migne). Paris, 1850. 
plena oración, detuvo al arquero, que le reconoció como humano y no animal59. Otra interesante anécdota la relata cuando unos cazadores perseguían a un animal por la calzada que transitaba Fructuoso y, nuevamente, la mala suerte hizo que éste se cruzara con los cazadores. Entonces la presa se escondió bajo la saya del clérigo y Fructuoso liberó al animal de una muerte segura a manos de los «malvados» ${ }^{60}$ cazadores.

En definitiva, los riesgos y la mala salud por accidente o enfermedad, así como la demanda de descanso en la ruta, junto al mayor número de viajeros (algo asociado a fines religiosos), propiciaron la creación de nuevos hospitales de peregrinos, que irán paulatinamente sustituyendo a las viejas mansiones ${ }^{6 I}$.

El riesgo de muerte en los viajes lleva a que en el título $\mathrm{V}$ de la Lex Visigothorum se plantee la siguiente cuestión: "Cómo se ha de confirmar la voluntad de aquel que muere en viaje (in itinere)». Se presenta así la necesidad de dejar un escrito, a modo de testamento, en el caso de que no exista una persona libre que acompañase en el viaje al fallecido ${ }^{62}$. Si el fallecido fuese iletrado, no quedaría otra alternativa más que delegar en un siervo u otra persona que ante un juez declarase las últimas voluntades del difunto en ruta ${ }^{63}$.

Otro inconveniente que queda recogido en este corpus legal era en relación con el desconocimiento de la ruta, es decir, ¿a qué se enfrentaba esa persona que iniciaba un camino nunca antes recorrido? Así pues, si bien la normativa sobre la construcción de fosos-trampa diseñados estaba directamente dirigida a la regulación de la caza, indirectamente podría afectar al viajero. Los fosos-trampa debían estar siempre notificados a los vecinos, pues de esta manera los lugareños quedaban descubiertos de la protección legal en el caso de caer en ellos; pero sí que se contemplaba el accidente si quienes lo sufrían eran animales. Igualmente, si una persona ajena a aquel territorio se accidentaba con un foso sin haber sido avisado del peligro existente, se le pagaría un tercio de lo establecido por la ley en caso de incapacidad o muerte, entendiendo que las trampas no estaban lo suficientemente lejos del camino ${ }^{64}$.

\section{APLICACIÓN DE LA LEY: PROTECCIÓN AL VIAJERO}

A lo largo de las páginas precedentes se ha realizado alguna alusión puntual a reglamentos jurídicos visigodos, que se refieren a cuestiones tales como la protección de los bienes del fallecido o a posibles accidentes en la ruta. En este

59. VF. 5 en DíAz y DíAz, Manuel C.: La vida de san Fructuoso de Braga. Estudio y edición crítica, Braga, 1974.

60. El adjetivo «malvados» define la opinión que éste tenía de la caza en zonas cercanas al monasterio en Castroleón (vf. 10) en DíAz y Díaz, Manuel C.: La vida de san Fructuoso de Braga. Estudio y edición crítica.

61. Szabŏ, Thomas: «Les dangers du voyage au Moyen Age. Problèmes et solutions», Siècles, Cahiers du centre $d^{\prime}$ histoire -Espaces et cultures 25 (2007), p.6o.

62. LV.V.11.

63. LV. 11.5 .13

64. LV.VIII.3.9 
apartado pretendemos presentar una visión global de las principales medidas legales que se llevaron a cabo para prevenir la seguridad de los viajeros. Tras los ejemplos anteriormente expuestos, cabe pensar que la labor regia centraría sus intereses en ofrecer seguridad al ciudadano y castigar de manera ejemplar al forajido. Efectivamente, la legislación de este período manifiesta una clara preocupación por controlar las actividades delictivas, lacra que, como ya hemos mencionado, fue heredada de las centurias romanas y que los propios preceptos romanos ya regulaba. En el caso del Digesto se enfatiza la necesidad de controlar a los bandidos y, por ello, la normativa legal debe ser de estricto cumplimiento para perseguir a los «sacrilegos latrones plagiarios fures» ${ }^{65}$.

El Codex Euricianus, en su apartado III De accusationibus, hace una mención especial a «ladrones de viajeros». Entre la amplia normativa relativa al castigo de los ladrones, así como a la regulación del caso de aquellos que en defensa propia matan a ladrones, aparece también el hurto de equipaje y su pena ${ }^{66}$. Se mantiene la percepción de esta medida en la Lex Visigothorum en lo tocante a los hurtos a gente que está de viaje, claro dictamen que protegería los bienes del que se encuentra «in itinere» ${ }^{67}$.

La ordenación euriciana contempla las necesidades viajeras en su apartado xxıI, De iter agentibus, respecto al permiso del viajero a transitar y vivaquear en campos abiertos. Se autoriza, incluso, a que el ganado del viajero pudiera pastar y a cortar «moderadamente» leña hasta un máximo de dos días, salvo expreso permiso del propietario (regulación exactamente duplicada por la Lex Visigothorum) ${ }^{68}$. Hay dos detalles que llaman la atención sobre este epígrafe; por un lado, que suele ser tradición repetida para todos los pueblos germánicos y, por otro, que no se especifica la multa al viajero que no cumpla con esta regla, pero sí, el caso de que fuera el propietario el que molestara al viajero, por ejemplo robándole pertenencias o el ganado ${ }^{69}$.

Por último, encontramos la tercera alusión a los viajeros dentro del Codex Euricianus en su apartado Ix, De vulneribus, en relación con las lesiones y daños. En esta sección se presentan diversos ejemplos, entre los que se incluye un caso especial, no directamente relacionado con lesiones sino con la retención de un viajero no-deudor ${ }^{70}$.

65. D. I.18.13. Véase nota 9

66. CE.III.17, edición consultada para esta y sucesivas referencias en Código de Eurico (edición, palingenesia, índices por A. d' Ors), $2^{\text {a }}$ ed. Madrid. Boletín Oficial del Estado, 2014.

67. LV.VIII.1.2.

68. VIII.4.27.

69. La multa ascendía al pago de un tercio de sueldo por cada dos cabezas de ganado robado. Si el propietario solo expulsaba al ganado para que no pastase en sus propiedades, se pagaría un tercio de sueldo por cada cuatro cabezas (Lv.4.36).

70. En el caso de deudores, ya sean viajeros o no, la normativa de Eurico, en el capítulo De vulneribus, explica el procedimiento sobre cómo ha de ser la correcta detención (CE. IX) 
Sobre los bienes materiales que tuviera la persona antes de partir, la Lex Visigothorum los protege de la siguiente forma: «De aquellos que hayan quitado algo a alguien que estuviere de viaje o haciendo un trabajo en el campo, o bien que hayan intentado causarle molestias ${ }^{7 \mathrm{7}}$. Se obliga, así, a aquel que haya aprovechado la ausencia de un propietario durante un viaje para ocupar sus tierras o para robarle algo, a restituir lo hurtado por cuadruplicado, y en el caso de haber matado a alguien la ley estudiaría el caso en particular. Si el delito lo cometiera un siervo, además recibiría Ioo azotes y la compensación económica por parte del amo (a no ser que prefiriera entregarlo a las autoridades). Por tanto, parece que se tiene en cuenta la garantía de posesiones durante la movilidad territorial bajo el amparo de la ley.

La regulación sobre el uso de carros y animales de tiro resulta significativa, al aludir expresamente al ataque en los bosques: «si in alienam silvan quis cum vehiculo capiatur» ${ }^{72}$. Aun así, la sanción se refiere más específicamente al robo de objetos personales o materiales propios del bosque, penando al ladrón si portase un carro, pues podría robar más cosas y transportarlas. Se permite así al dueño del terreno a quedarse con dicho carro. No existe alusión directa respecto a qué ocurre cuando los viajeros que circulaban en un carruaje eran asaltados, sino que, por el contrario, solo se valora la posibilidad de que el ladrón tuviera un carro en el que poder transportar lo robado, tipo «aros para las botas o cualquier clase de madera».

Otra medida contra los ladrones, aunque en este caso no se específica que fuesen en particular de caminos, son los crimina. En estos códices legales se expresa la preocupación por controlar y castigar los robos y hurtos. Parece que el hurto era considerado más grave, pues se propone una pena mayor al vincularse con una actividad que solía realizarse aprovechando la oscuridad de la noche ${ }^{73}$. Esta idea nos recuerda el pensamiento del propio Isidoro de Sevilla ${ }^{74}$, quien definía al latro como aquel que delinquía en lo «sombrío»75.

Por último, el Código teodosiano refleja la preocupación por la lacra que suponía tener bandidos perturbando la seguridad del viandante. Por ello, incide en la importancia de que la ley sea cumplida de manera rigurosa sobre criminales

\footnotetext{
71. LV.VIII.1.12.

72. LV.VIII.3.8.

73. LV.VII.

74. Isidoro basa la definición de «ladrón» en la idea del propio Varrón, indicando que latere significa esconderse; por tanto, el ladrón o asaltador de caminos estaría escondido para atacar de improviso a su víctima. No queda claro si Isidoro consideraba que la gente que se dedicaba a esas actividades era por necesidad, y de esa manera se podía llegar a comprender por qué actuaban al margen de la ley: Isid. Etym. X. 159. «Latro inssesor viarum...». Existe una segunda referencia en Isidoro de Sevilla concerniente a «fur», ladrón, que deriva de furvus u oscuro, por tanto, aquel que trabaja en lo sombrío: Isidoro De Sevilla. Etimologías (edición bilingüe, Madrid, Ed. J. Oroz Reta, M. Marcos Casquero, M. Díaz y Díaz), Vol. 1, 1982.

75. Parece que las actuaciones de bandidaje durante la noche fueron algo común, tal y como confirman las fuentes. Para el caso cristiano, además, tiende a vincularse con la aparición del diablo y el pecado. Sobre la actividad nocturna de los bandidos, véase NERI, Valerio: I marginali nell' Occcidente tardoantico. Poveri, «infames» e criminali nella nascente società cristiana, Bari, Edipuglia, 1998, pp. 386-391.
} 
y bandidos $^{76}$; cualquier colaboración con éstos, llevaría a la quema ${ }^{77}$. Además, protegería al viajero permitiéndole el uso de violencia y armas contra aquellos asaltantes que quisieran cometer un robo contra su persona, haciendo alusión a lo común que eran las emboscadas en caminos durante la noche $\mathrm{7}^{8}$.

\section{CONCLUSIONES}

No cabe duda de que viajar ha sido y es una necesidad de las sociedades humanas desde el inicio de los tiempos. Los propósitos y las comodidades del viaje han ido evolucionando con los siglos, y así mismo los peligros e inseguridades han ido transformándose. Durante la tardoantigüedad, los contratiempos derivados de los desplazamientos eran variados, pudiendo incluso llegar a peligrar la propia vida del viajero. La preocupación de los gobernantes por fiscalizar los asaltos e imponer justicia quedaron patentes en los diversos reglamentos conservados tanto para el mundo romano como posteriormente bajo el domino visigodo. El pillaje y bandidaje a los viajeros fue algo común durante el mundo grecorromano, y para el periodo visigodo son numerosas las alusiones (en particular de los siglos vı y viı) en las hagiografías, en las que están muy presentes los asaltos como una «penitencia» que todo buen hombre debía padecer ${ }^{79}$. Y es que el género literario hagiográfico nos ha permitido reconstruir formas de viajar durante las centurias de transición a la Alta Edad Media. Tal y como ha quedado de manifiesto en los ejemplos seleccionados, la mayor parte de los viajes documentados para este período eran realizados por clérigos. La lectura de sus vidas nos ha permitido redefinir la imagen del poder cristiano ante la suerte de la ultio diuina, la protección del santo viajero. Durante las odiseas vividas por estos santos en sus desplazamientos,

76. CTh.1.29.8.

77. CTh.7.1.1.

78. CTh.9.14.2; Véase nota previa (77).

79. Nos referimos, por ejemplo, a los textos de San Agustín, el cual alude a los asaltantes de caminos y la protección de Jesús durante el peregrinaje (Sermo 306, 2, De patientia 5, 4, Pasionis 66, 6) en SAN Agustín, Obras completas. xxv: Semones $\left(5^{\circ}\right.$ ): 273-338. Traducción y notas de P. de Luís Vizcaíno y J. Anoz Gutiérrez. Madrid, Ed. Biblioteca de autores cristianos, 2017. Agustín llega a emplear el término «ladrones - praedonis» para adversarios político-ideológicos, de manera despectiva, describiéndolos como peores incluso que los bárbaros: DIESNER, Hans- Joachim: «Augustinus und die Barbaren der Völkerwanderung», Revue d'études augustiniennes et patristiques 23 (1-2) (1977), PP. 83-91; POTTIER, Bruno: «Les dangers du voyages: banditisme et insécurité sur les routes aun IV et $V^{e}$ siècles», Antiquité Tardive 24 (2016), pp. 137-148. Otro ejemplo lo localizamos en la obra De civitate Dei contra paganos, cuando San Agustín considera que las bandas de bandidos son el resultado de un régimen degenerado, alejado de Dios: «Si de los Gobiernos quitamos la justicia, ¿en qué se convierten sino en bandas de ladrones a gran escala? Y estas bandas, ¿qué son sino reinos en pequeño? Son un grupo de hombres, se rigen por un jefe, se comprometen en pacto mutuo, reparten el botín según la ley por ellos aceptada. Supongamos que a esta cuadrilla se le van sumando nuevos grupos de bandidos y llega a crecer hasta ocupar posiciones, establecer cuarteles, tomar ciudades y someter pueblos». Libro IV. Cap. IV en SAN Agustín: Civitate Dei contra paganos. Libro Iv (traducción S. Santamarta, M. Fuertes). Madrid, 1988.

Otro ejemplo lo localizamos en la vida de San Fructuoso (VF 7, 11,12). 
siempre se presenta un «hecho milagroso» que protege la vida del protagonista, cómo no, gracias a la omnipotencia divina ${ }^{80}$.

El problema de la violencia nunca consiguió erradicarse y, consecutivamente, en la legislación bajomedieval se perpetuarán las mismas ideas vigentes desde la antigüedad, observándose cómo en las normas viarias estará presente lo que se denominará «la paz del camino», canon por el cual los gobernantes debían responder ${ }^{8 \mathrm{I}}$.

Todo viajero tardoantiguo se adentraba en parajes nunca vistos, en los que podría sufrir robos, asesinatos, ultrajes, hambre, enfermedades... Era sabido que emprender un viaje no sería algo placentero, sencillo o barato. No obstante, desde tiempos antiguos los nobles podían realizar desplazamientos por placer, huyendo de las tumultuosas ciudades al campo. Otros viajes podrían ser por negocio, asociados al intercambio de mercancías, y también existieron los viajes con una finalidad religiosa, con más importancia en la Antigua Grecia que en Roma y que, posteriormente, recobran protagonismo en la tardoantigüedad, no solo con el peregrinaje sino también con el monacato religioso, como se transmite en las vidas de los santos ${ }^{82}$.

Ha quedado probada la existencia de delincuencia asociada a la extorsión de los viajeros en diversas rutas de la Hispania visigoda, una delincuencia que era llevada a cabo por ladrones que, en ocasiones, podrían contar con la colaboración y solidaridad de algunos individuos de clases bajas, como campesinos, esclavos fugados o guerreros de tribus «no civilizadas» ${ }^{83}$. Estos ejemplos los podemos deducir de la regulación de la Lex Visigothorum sobre «De fugitivis et refugientibus» ${ }^{84}$. También, se ha confirmado que algunos actos de pillaje vinieron derivados de desórdenes militares generados por las propias milicias durante crisis de poder o movimientos expedicionarios. Así, asaltaban los pueblos de paso en busca de los recursos necesarios para un avituallamiento en campaña.

Tras el análisis de todas las fuentes presentadas, hemos observado cómo en estos textos los términos «bandido» y «ladrón» son empleados de manera indistinta, aludiendo a los salteadores de caminos cuya actividad iba ligada a la violencia, y en especial a actos atroces en zonas rurales más alejadas de la población. Más en particular, observamos cómo la legislación visigoda refleja la baja consideración social hacia el esclavo, ladrón y fugitivo, casi de igual manera. Pese a las sanciones

80. GARCíA DE LA BorbolLA, Ángeles. «El universo de los maravilloso en la hagiografía castellana». Boletín de la Real Académica de Buenas Letras de Barcelona 47 (2000), pp.335-351.

81. Diago, Máximo y LADERo, Miguel Ángel: «Caminos y ciudades en España de la Edad Media al siglo XVIII», En la España Medieval, 32 (2009), pp.352-353.

82. Si bien la creación de la red de calzadas romanas indudablemente tuvo que mejorar el transporte de pasajeros y mercancías, los riesgos no disminuyeron ni por tierra ni por mar. En la navegación habría que contar con un buen barco y, al igual que en los viajes terrestres, hacer frente a las condiciones climáticas, a las enfermedades y a la piratería: véase GonZALbES, Enrique: Viajes y viajeros en el mundo antiguo, Cuenca, Universidad de Castilla- La Mancha, 2003, pp.24-26.

83. DIESNER, Hans- Joachim: «Bandas criminales, bandidos y usurpadores en la España visigoda», Hispania Antiqua vIII (1978), pp.137; GARCíA, Luis A.: El fin del reino visigodo de Toledo: decadencia y catástrofe: una contribución a su crítica, p.76.

84. LV.IX.1. 
legislativas, la delincuencia viaria fue una lacra que perduró durante toda la antigüedad y también la Edad Media ${ }^{85}$.

Si bien es cierto que el tema de la violencia ejercida por ladrones debió de ser el más preocupante de todos los problemas posibles de un viaje, tal y como hemos expuesto, existieron además otras preocupaciones que se alejaban de la acción humana y que no eran previsibles, tales como las condiciones de las vías o la propia climatología, en definitiva nuevas experiencias nunca antes vividas y que obstaculizarían más aún los tiempos y la confortabilidad del viaje.

85. Posiblemente, para el mundo tardoantiguo vino dado por la ligereza de las penas, pues en el Digesto $(48,6.11$ Paulus) la pena de muerte era el castigo a las fechorías de los bandidos, mientras que en la normativa de Chindasvinto (LV.VIII.4.1) observamos cómo los castigos se reducen a azotes, multas y otras penas menores. 


\section{FUENTES CITADAS}

Amiano Marcelino: Historia (traducción por M. L. Harto Trujillo). Madrid, Ed. Akal, 2002.

Braulio de Zaragoza, Isidoro de Sevilla: Epistulae, Confessio uel professio Iudaeorum ciuitatis Toletanae (eds. R. Franco Miguel, J.C. Martín-lglesias). Corpus Christianorum, Series Latina (CCSL II4B), Turnhout, Brepols, 2018.

Braulio de Zaragoza: Vita Sancti Aemiliani, (ed. J. P. Migne). Paris, I850.

Cipriano de CARTAGo: Cartas $\left(\mathrm{M}^{\mathrm{a}}\right.$. L. García Sanchidrián, Introducción, traducción y notas). Madrid, Ed. Gredos, n ${ }^{\circ} 255$, I998.

Código de Eurico (ed. palingenesia, índices A. d' Ors), $2^{\mathrm{a}}$ ed. Madrid, Boletín Oficial del Estado, 2014.

Codex Theodosianus (ed. T. Mommsen y P. M. Meyer) 2 vols. Berlín: Weidmann, I905.

Codici Theodosiani. Lex romana Visigothorum. Fragmenta et Codice Palimpsesto (ed. Regia Historiae Academia hispana), New York, I896.

Concilios visigóticos e Hispano-romanos (ed. J. Vives), Vol. I, Barcelona-Madrid, csic, I963.

Cuerpo del derecho civil romano. T. III. Digesto (traducción y compilación I. García del Corral). Barcelona: [ed.J. Molinas], I897.

Fructuoso de Braga: (ed. M. Díaz y Díaz). La vida de san Fructuoso de Braga. Estudio y edición crítica, Braga, I974.

Gregorio DE Nisa: Lettres (introduction, texte critique, traduction, notes et index P. Maraval). Paris, Sources Chrétiennes, $\mathrm{n}^{\circ}$ 363, 1990.

Gregorio DE Tours: Historianum libri X (eds. B. Krusch, W. Levison, M.G.H). ss. I. Hannover, I888.

HidACıO: The Chronicle of Hydatius and the Consularia Constantinopolitana (ed. with English translation by R.W. Burgess), Oxford, Clarendon Press, I993.

Isıdoro de Sevilla: Etimologías (ed. bilingüe J. Oroz Reta, M. Marcos Casquero, M. Díaz y Díaz). Vol. I, Madrid, I982.

Julı́́n DE Toledo: Historiae de Wambae regis Gothorum Toletani expeditione. Monumenta Germaniae Historica, T.5. Hannover, I9I0.

Laureano de Obispo Metropolitano de Sevilla y Mártir: Parte primera danse sus actas purgadas, y sostenidas contra las modernas impugnaciones (ed. D. Tello Lasso de la Vega), Sevilla, I758.

Liber Iudiciorum (estudio preliminar R. Ramis Barceló; traducción y notas P. Ramis Serra y R. Ramis Barceló). Madrid: Agencia Estatal Boletín Oficial del Estado, 2015.

Rutilio Namaciano: De reditu suo. El retorno - Geógrafos latinos menores (introducción, traducción y notas A. García-Toraño Martínez). Madrid, Ed. Gredos, 2003.

SAn Agustín: Obras completas. xxv: Semones $\left(5^{\circ}\right): 273-338$. (traducción y notas P. de Luís Vizcaíno y J. Anoz Gutiérrez). Madrid, Ed. Biblioteca de Autores Cristianos, 2017.

San Agustín: Civitate Dei contra paganos. Libro iv (traducción S. Santamarta, M. Fuertes). Madrid, I988.

Santos Padres Españoles II. San Leandro, San Fructuoso, San Isidoro. Reglas monásticas de la España visigoda. Los tres libros de las «Sentencias» (ed. crítica bilingüe J. Campos e I. Roca). Madrid, Biblioteca de Autores Cristianos, I97I.

Sulpicio SEvero: Vita Martini (ed. P. Burton), Oxford, 2017.

Vida de los Santos Padres de Mérida (introducción, traducción y notas I. Velázquez). Madrid, Ed. Trotta, 2008. 
Vitae sanctorum patrum Emerentensium, (ed. A. Sánchez Maya). Corpus Christianorum, Series Latina Iı6, Turnhout, Brepols I992.

\section{BIBLIOGRAFÍA CITADA}

AjA, José Ramón: «Cantabria en la Antigüedad tardía», en AJA, José Ramón, Cisneros, Miguel, RAmírez, José Luis (coords.), Los cántabros en la antigüedad: la historia frente al mito, Santander, Universidad de Cantabria, 2008, pp. I9I-228.

ARCE, Javier: «El Cursus publicus en la Hispania tardorromana», en Actas del Simposio sobre la red viaria en la Hispania romana, celebrado en Zaragoza del 23-27 de Septiembre de I987, Zaragoza, I990, pp. 35-40.

ARCE, Javier: Bárbaros y romanos en Hispania 400-507 A.D. Madrid, Ed. Marcial Pons, 2007.

BARENAS, Ramón: La articulación eclesiástica del Valle Medio del Ebro y su área de influencia (ss. III-VIII), Tesis doctoral, Universidad de La Rioja, Inédita, 2015.

BlÁzQuez, José María: «Hispanos en visita a Roma y al Oriente en los siglos IV y V», en Bravo, Gonzalo y GonzÁLez, Raúl (eds.), Ver, viajar y hospedarse en el mundo romano. Madrid, Ed. Signifer, 2012, pp.I5I-I69.

Bravo, Gonzalo: «Acta bagaudica (I): sobre quiénes eran «bagaudas» y su posible identificación en los textos tardíos». Gerión, 2, (I984), pp. 25I-264.

Bravo, Gonzalo: «Los Bagaudas: vieja y nueva problemática». Actas del ter. Congreso Peninsular de Historia Antigua. Santiago de Compostela, I-5 julio I986, Vol. 3, (I988), pp. I87-I96.

Bravo, Gonzalo: «La hospitalitas tardorromana: ¿tradición o innovación?» en Bravo, Gonzalo, GonzÁlez, Raúl (eds.), Ver, viajar y hospedarse en el mundo romano. Madrid, Ed. Signifer, 2012, pp.205-220.

BrélAz, Cédric: La sécurité publique en Asie Mineure sous le Principat ( $\left({ }^{e r}-I I I^{\text {ème }}\right.$ S. ap. J.-C.). Bassell, Schawabe Verlag, 2005.

Clifford, E. Minor: «'Bagaudae’ or 'Bacaudae’? », Traditio, 3I, (I975), pp. 3I8-322.

Clifford, E. Minor: « Bacaudae: a Reconsideration», Traditio, 5I, (I996), pp. 297-307.

Collins, Rogers: La España visigoda 409-7II, Barcelona, Ed. Crítica, Traducción por M. García Garmilla, 2004.

Diago, Máximo y Ladero, Miguel Ángel: «Caminos y ciudades en España de la Edad Media al siglo xviı», En la España Medieval 32 (2009), pp. 352-353.

Díaz, Pablo, C.: «Redimuntur captivi. A propósito de la Regula Communis IX», Gerión Io (I992), pp. 287-293.

Díaz, Pablo, C.: «El peregrino y sus destinos: los lugares de Cristo», en Marco Simón, Francisco, Pina, Francisco y Remesal, José (eds.), Viajeros, peregrinos y aventureros en el mundo antiguo, Barcelona, Publications i Editions de la Universitat de Barcelona, 20I0, pp. 24I-266.

DíAz, Pablo C.: El reino Suevo 4II-585. Madrid, Ed. Akal, 20II.

Díaz, Pablo C., Martínez, Clelia y Sanz, Francisco Javier: La Hispania tardoantigua y visigoda, Historia de España, $n^{\circ}$ V, Madrid, Ed. Itsmo, 2007.

Díaz y Díaz, Manuel C.: Valerio del Bierzo. Su persona. Su obra, León, Centro de Estudios e investigación «San Isidoro», 2006.

Diesner, Hans- Joachim: «Augustinus und die Barbaren der Völkerwanderung», Revue d" études augustiniennes et patristiques 23 (I-2) (I977), pp. 83-9I. 
Diesner, Hans- Joachim: «Bandas criminales, bandidos y usurpadores en la España visigoda», Hispania Antiqua vill (I978), pp. I29-I42.

Díez, Carmen: «Hacia la Edad Media: jadvenimiento de nuevas formas de organización social y territorial?», en AjA, José Ramón, Cisneros, Miguel y Ramírez, José Luis (coords.), Los cántabros en la antigüedad: la historia frente al mito, Santander, Universidad de Cantabria, 2008, pp. 265-278.

Domínguez Del VAL, Ursicino: Leandro de Sevilla y la lucha contra el arrianismo. Madrid, Ed. Nacional, I98I.

Friguetto, Renan: Valério do Bierzo. Autobiografia, Serie Trivium, La Coruña, 2006.

Funrmann, Christopher: Policing the Roman Empire, New York, Ed. Oxford University Press, 2012.

GARCíA, Luis A.: El fin del reino visigodo de Toledo: decadencia y catástrofe: una contribución a su crítica, Madrid, Universidad Autónoma de Madrid, 1975.

García, Luis A.: Historia de España visigoda, Madrid, Ed. Cátedra, I989.

García, Luis A.: España, Siglo V. La Monarquía goda Balta y la Diócesis de las Españas, Madrid, Real Academia de la Historia, 2017.

GARCíA DE la Borbolla, Ángela: «El universo de los maravilloso en la hagiografía castellana». Boletín de la Real Académica de Buenas Letras de Barcelona 47 (2000), pp.335-35I.

GonZalbes, Enrique: Viajes y viajeros en el mundo antiguo, Cuenca, Universidad de CastillaLa Mancha, 2003.

GonZÁLEZ, Julián: «Interrex y occisus est ab latronibus», en J. Higueras Maldonado (coord.), Actas del I Congreso Andaluz de Estudios Clásicos (Jaén, I98I), Jaén, I982, pp. 223-227.

IgLESIAS, José Manuel y Ruız, Alicia (eds.): Viajes y cambios de residencia en el mundo romano, Santander, Universidad de Cantabria, 2orI.

IsLA, Amancio: «Los fugitivos y el título sobre ellos del Liber ludicum», Arqueología y Territorio Medieval 8 (2OII), pp. II3-I24.

JaCQUET-Rimassa, Pascale, Hoffmann, Genevière, NADAL, Eléonore y Cassimatis, Hélène: Voyages en Antiquité. Mélanges offerts á Hélène Gruiraud, Pallas, Revue d'Études Antiques $76,2008$.

JimÉNEZ, Jesús: «Hospedajes para viajeros en el Imperio romano», enMorère, Nuria, (coord.), Viajes en el Mediterráneo antiguo,Madrid, Editorial Universitaria Ramón Areces, 2009, pp. I6I-I8I.

KARR, Karen Eva: «A Changing world-African Slip in Roman and Visigothic Baetica», en Ferreiro, Alberto (ed.), The Visigoth studies in culture and society, Leiden-Boston-Köln, Ed. BRILL (I999), pp. 219-262.

KuUliala, Jenni y RANTALA, Jussi (eds.): Travel, pilgrimage and social interaction from Antiquity to the Middle Ages, London, Ed. Routledge, 2020.

LAURENCE, Ray: «The meaning of roads: a reinterpretation of the Roman Empire», en KuUliala, Jenni y Rantala, Jussi (eds.), Travel, pilgrimage and social interaction from Antiquity to the Middle Ages, London, Ed. Routledge, 2020, pp. 28-4I.

Maraval, Pierre: Lieux saints et pelerinages d' Orient. Histoire et géographie. Des origines à la conquête árabe, Paris 1985.

Marco, Simón, Francisco, Pina, Francisco y Remesal, José (eds.): Viajeros, peregrinos y aventureros en el mundo antiguo, Barcelona, Publications i Editions de la Universitat de Barcelona, 20I0.

MARTín, José Carlos: «¿Valerio en Compludo? Examen crítico de los opúsculos autobiográficos (CPL I282-I284) y las visiones del más allá (CPL I277-I279) de Valerio del Bierzo», Veleia 23 (2006), pp.327-338. 
MarTínez, Pedro: El pensamiento histórico y antropológico de Orosio. Antigüedad y Cristianismo. Murcia, Universidad de Murcia, Monografías históricas sobre la antigüedad tardía, XIX, 2002.

Morène, Nuria, (coord.), Viajes en el Mediterráneo antiguo, Madrid, Editorial Universitaria Ramón Areces, 2009.

NARro, Ángel: Vida y Milagros de Santa Tecla, Madrid, Biblioteca de Autores Cristianos, 2017.

Neri, Valerio: I marginali nell' Occciednte tardoantico. Poveri, «infames» e criminali nella nascente società cristiana, Bari, Edipuglia, I998.

NERI, Valerio: I prigioneri romani dei barbari nella società dell' Occidente tardoantico (IV-VI sec.), en VAllejo, Margarita, Bueno, Juan Antonio y Sánchez-Moreno Ellart, Carlos, (eds.), Movilidad forzada entre la Antigüedad Clásica y Tardía, Alcalá de Henares, Universidad de Alcalá, 2015, pp.75-90.

Pérez, Dionisio: «Problemas sociales del reino visigodo de Toledo», Studia Historica, Historia Antigua I (1983), pp. I05-II7.

Petraccia, María Federica: Gli «stationarii» in età imperiales, Roma, Ed. Serta Antiqua et Medievalia, III, 200I.

Ponte, Vanessa: Régimen jurídico de las vías públicas en el derecho romano, Madrid, Ed. Dykinson, 2007.

PotTIER, Bruno: «Les dangers du voyages: banditisme et insécurité sur les routes aun $\mathrm{IV}^{\mathrm{e}}$ et Ve siècles», Antiquité Tardive 24 (2016), pp. I37-I48.

Rodríguez, Antonio: Aquae Flaviae: I. Fontes epigráficas da Gallaecia meridional interior, Chaves, 1997.

Ruız, Alicia: «Viajes y prácticas culturales en las provincias romanas de Hispania y la Galia» en IgLESias, José Manuel y Ruiz, Alicia (eds.): Viajes y cambios de residencia en el mundo romano, Santander, Universidad de Cantabria, 20II, pp. 20I-224.

SÁNCHEZ, Jesús: «¿Bandidos lusitanos o pastores trashumantes?», Hispania Antiqua Xxi (1997), pp. 69-92.

ScheIN, Sylvia: «The Female-men of God and Men who were women: Female Saints and Holy land pilgrimage during the Byzantine period», Hagiographica 5 (I998), pp. I-36.

SHaw, Brent: «Bandits in the Roman Empire», Past \& Present I05 (I) (I984), pp 3-52.

SzABŎ, Thomas: «Les dangers du voyage au Moyen Age. Problèmes et solutions», Siècles, Cahiers du Centre d' Histoire -Espaces et Cultures 25 (2007), pp. 5I-66.

Thompson, Edward Arthur: «Peasant Revolts in Late Roman Gaul and Spain», Past \& Present 2 (1952), pp.II-23.

VAlverde, María Rosario: Los viajes de los reyes visigodos de Toledo (53I-7II), Madrid, Ed. La Ergástula, 20I7.

VAN Tilburg, Cornelis: Traffic and congestion in the Roman Empire, London, Ed. Routledge, 2007. 
Calidad de Revistas

científicas Españolas

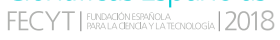

SERIE III HISTORIA MEDIEVAL

REVISTA DE LA FACULTAD DE GEOGRAFİA E HISTORIA
AÑO 2021

ISSN: 0214-9745

E-ISSN 2340-1362

\section{4 \\ issacio. \\ TIEMPO \\ Y FORMA}

\section{Volumen I}

\section{Artículos · Articles}

15 Patricia A. Argüelles Álvarez

Peligros, inseguridades y problemas del viajero visigodo

37 Carmen Barceló, Ana labarta, Josep Benedito \& José M. MELCHOR

Cuatro cerámicas con epigrafía árabe del Museu de Borriana

65 CARlos BARQuero Goñ

Organización de la Orden de San Juan en Castilla durante los siglos XII y XIII

113 Francisco de Paula Cañas Gálvez

Una infanta de Navarra en la corte de Castilla: escenarios políticos en torno a la configuración y evolución del Hostal y la casa de Blanca de Trastámara, Princesa de Asturias (1424-†1464)

\section{David Caramazana Malia}

Las promociones artísticas de Alonso de Ejea, arzobispo y administrador perpetuo de la Archidiócesis de Sevilla y patriarca de Constantinopla (1403-1417)

\section{Pedro Castillo Maldonado}

Privilegios episcopales: la inviolabilidad de los obispos visigóticos y el delito de lesa majestad

\section{MÁxIMO DIAGO HERNANDO}

Alonso de Fonseca, Obispo de Ávila, Cuenca y Osma, y el ascenso de un linaje de exiliados portugueses en la Castilla de los siglos XV y XVI

\section{Antonio PIO dI Cosmo}

Santa Brigida ed il Monte Gargano: un paesaggio dell'anima. La descrizione dell'ambiente come stratagemma d'ammaestramento morale

\section{FERRAN ESQUILACHE}

La 'fila' de agua valenciana y otras medidas de aforo. La verdadera naturaleza de un sistema de medición de caudales de origen andalusí

\section{Alejandro Esteban Álvarez}

Habices del Reino de Granada averiguados en 1528 y 1531: la țā'a nazarí de Órgiva (Alpujarra)

\section{JaVier Gómez Gómez \& IÑAKı MARTín VISO}

Rationes y decimas: evidencias sobre la gestión de las sernas en el siglo XI en el noroeste de la Península Ibérica
383 SANTIAGO GONZÁLEZ SÁNCHEZ

Aportaciones de Paredes de Nava a las campañas militares de Infante Don Fernando, señor de la villa y regente de Castilla, contra el Reino Nazarí de Granada en 1407 y en 1410

429 ANTONI LLIBRER ESCRIG

Una máquina para la industria medieval. Los batanes del sur valenciano: integración y negocio. Nuevas aportaciones (1490-1502)

455 José Miguel López Villalba Comunicación escrita y oral de la ordenanza municipa (siglos XV-XVI)

501 Emilio Martín Gutiérrez

El aprovechamiento de los recursos naturales: la grana en Andalucía occidental durante el siglo XV

\section{Volumen II}

537 VERA-CRuz Miranda MENACHO

$(1421-1461)$

Las finanzas de un heredero: Carlos de Aragón y Navarra

569 Raúl Morales Muñoz

Hacia una revalorización del conciliarismo hispano bajomedieval: el Defensorium Trium Conclusionum de Alfonso de Madrigal

605 David Nogales Rincón

Enrique III de Castilla (1390-1406) y la indagación de rentas: un proyecto regio para la búsqueda de mineros y tesoros a inicios de cuatrocientos

6.7.7 Gonzalo Oliva Manso

Seisenes y novenes. Tiempos de calma para la moneda castellano-leonesa (1282-1312)

685 Alberto Peña Fernández y Manuel García Alonso Una inscripción medieval inédita en la iglesia de San Miguel de Aguayo (Cantabria)

713 RODRIGO POUSA DIÉGUEZ

Configuración institucional de una villa costera: Muros en el tránsito de la Edad Media a la Edad Moderna

\subsection{JuAn A. Prieto Sayagués}

Las profesiones femeninas de la nobleza y de las oligarquías urbanas en la Castilla bajomedieval. Causas, dinámicas, privilegios y donaciones 


\section{4}

\section{ESPACIO,}

\section{TIEMPO}

Y FORMA

UกED

SERIE III HISTORIA MEDIEVAL

REVISTA DE LA FACULTAD DE GEOGRAFÍA E HISTORIA

815 María del Pilar Rábade Obradó

El miedo a la Inquisición en la Castilla de los Reyes Católicos

84.5 Carlos Manuel Reglero de la Fuente

EL abad contra el rey (y los regidores): conflicto de jurisdicciones y ejercicio del poder en Sahagún (1398-1417)

881 Manuel Alejandro Rodríguez de la Peña

Eusebius and Alcuin on Constantine and Charlemagne as Wise Rulers: Sapiential Rulership in Late Antiquity and the Early Middle Ages

9)15 Antonio SÁnCHEZ GonzÁlez

El Archivo de los Mariscales de Castilla y Marqueses de Malagón

\section{Estudios y comentarios}

9. 51 Serafín Olcoz Yanguas

Apostilla al estudio Influencia de las redes nobiliarias en la expansión cristiana del siglo XII: el caso de Soria (ETF, 33, 2020)

\section{Libros · Books}

969 CAstrillo CASAdo, Janire, Las mujeres vascas durante la Baja Edad Media (MARía Jesús Fuente)

973 Crónica del rey Juan II de Castilla. Minoría y primeros años de reinado (1406-1420) GARCIA, Michel (edición y estudio) (VÍctor MUÑ̃z GómEZ)

981 DA Silva, Marcelo Cândido, História Medieval (DIEgo CARLo AMÉNDOLLA SPÍNOLA)

9.87 Galende Díaz, Juan Carlos y Ávila SeoAne, Nicolás, El rodado regio hispánico. Fernando III de León y Castilla (12301252) (MAURICIO HERRERO JIMÉNEZ)

989 García IzQuierdo, Iván, Frontera, fuero y concejos. EI valle del Riaza en la Edad Media (siglos VIII-XII) (CARLOS BARQUERO GOÑI)

993 García IzQuierdo, Iván y Peterson, David (coords.), Camino y Señorío. Obra selecta de Luis Martínez García (ENRIQUe CANTERA MONTENEgRO)

995 GonzÁlez PAz, Carlos Andrés, O Bispado de Mondoñedo na Idade Media. Territorio, comunidade e poder (ENRIQUE CANTERA Montenegro) 


\section{4}

\section{ESPACIO,}

\section{TIEMPO}

Y FORMA

UกED

SERIE III HISTORIA MEDIEVAL

REVISTA DE LA FACULTAD DE GEOGRAFİA E HISTORIA

\section{Libros · Books}

9) López MARtínez, Amalia, Minutarios notariales de Estevo Pérez (Ourense, siglo XIV) (José MIgUel LóPEz VILLALBA)

999 Miranda García, Fermín y López de Guereño SAnz, María Teresa (eds.), La muerte de los príncipes en la Edad Media. Balance y perspectivas historiográficas (ANA ECHEVARRÍA ARSUAGA)

1003 Motis Dolader, Miguel Ángel, Vivencias, emocionesy perfiles femeninos. Judeoconversas e Inquisición en Aragón en el siglo XV (ANA ECHEVARría ARsuaga)

1007 Solórzano Telechea, Jesús Ángel y Martín PÉrez, Fernando (coords.), Rutas de comunicación marítima y terrestre en los reinos hispánicos durante la Baja Edad Media. Movilidad, conectividad y gobernanza (ENRIQUE JOSÉ RUIZ PILARES)

1013 TORRE, Sandra de la - ETXEBERRIA, Ekaitz - DíAz DE DURANA, José Ramón (coords.), Valer más en la tierra. Poder, violencia y linaje en el País Vasco bajomedieval (ENRIQUE CANTERA MONTENEGRO)

1015 TRILlo SAN José, Carmen, La Vega de Granada a partir de documentación árabe romanceada inédita (1457-1494). Estudio, edición e índices (INMACULADA GONZÁLEZ SOPEÑA)

1019 Val Valdivieso, M. ${ }^{a}$ Isabel - VillanueVa ZubizarReta, Olatz (Coords.), Pero Ansúrez. El conde, su época y su memoria (ENRIQUe CANTERA MONTENEGRO)

1021 Villanueva Morte, Concepción y Fernández de Córdova Miralles, Álvaro, El embajador Claver. Diplomacia y conflicto en las «Guerras de Italia» (1495-1504) (ENRIQUE Cantera Montenegro) 